\title{
Validation of hydrogeochemical databases for problems in deep geothermal energy
}

\author{
Thorsten Hörbrand ${ }^{1,2^{*}}$ (D) Thomas Baumann ${ }^{2}$ and Helge C. Moog ${ }^{3}$
}

\author{
*Correspondence: \\ t.hoerbrand@gmail.com \\ ${ }^{1}$ Erdwerk GmbH, Bonner \\ Platz 1, 80803 München, \\ Germany \\ Full list of author information \\ is available at the end of the \\ article
}

\begin{abstract}
Hydrogeochemical modelling has become an important tool for the exploration and optimisation of deep hydrogeothermal energy resources. However, well-established software and model concepts are often run outside of its temperature, pressure, and salinity ranges. The core of the model codes are thermodynamic databases which contain a more or less complete subset of mineral phases, dissolved species, and gases occurring in geothermal systems. Although very carefully compiled, they should not be taken for granted at extreme conditions but checked prior to application. This study compares the performance of four commonly used geochemical databases, phreeqc. dat, IInl.dat, pitzer.dat, and slop16.dat. The parameter files phreeqc.dat, pitzer.dat, and IInl.dat are distributed with PHREEQC and implement extended Debye-Hückel and Pitzer equations. Thermodynamic data in slop 16.dat represent an implementation of the revised Helgeson-Kirkham-Flowers formalism and were converted to be used with the Gibbs Energy Minimizer ChemApp for this work. Test calculations focussed on the solubility for some of the most common scale-forming mineral phases (barite, celestite, calcite, siderite, and dolomite). The databases provided with PHREEQC performed comparatively well, as long as the range of validity was respected for which the corresponding database was developed. While it is obvious to use pitzer.dat at high salinities instead of phreeqc.dat, the range of validity for high temperature is usually not given in the database and has to be checked manually. The results also revealed outdated equilibrium constants for celestite in slop16.dat and IInl.dat and the lack of adequate temperature functions for the solubility constants of siderite and dolomite in all databases. For those two minerals, new thermodynamic data are available. There is, however, a lack of experimental thermodynamic data for scale-forming minerals in low-enthalpy geothermal settings, which has to be addressed for successful modelling.
\end{abstract}

Keywords: Hydrogeochemical modelling, Thermodynamic database, Geothermal, PHREEQC, ChemApp, HKF

\section{Background}

Geothermal energy has acquired a key position in the mix of renewable energies due to its very effective heat supply and the ability to provide base load electrical energy. Many current model concepts addressing deep geothermal exploration focus on thermal, mechanical, and hydraulic interactions (e.g. Gholizadeh Doonechaly et al. 2016; Magnenet et al. 2014; Major et al. 2018; Yoon et al. 2014; Zhao et al. 2015), while neglecting hydrogeochemical effects. This is partly due to a lack of experimental data for short-term hydrogeochemical processes in the vicinity of production and injection wells (Baumann 
et al. 2017). Ambitious facilities running at high volumetric flow rates and temperatures revealed that even small changes of the hydrochemical equilibria can lead to serious problems with precipitations in subsurface and surface level facilities. Such precipitations tend to clog casings, heat exchangers, and submersible pumping systems of the facility and may even lead to porosity reduction in the reservoir. Any of these risks can lead to economically adverse situations for the operator, due to the necessity of maintenance and plant downtime. This has led to an increasing awareness for hydrochemical processes in the engineering community.

Hydrogeochemical models are applied in order to predict precipitation reactions in surface level facilities and hydraulic changes induced by hydrogeochemical reactions in the reservoir (e.g. Baumann et al. 2017; Fritz et al. 2010; Nitschke et al. 2017; Reed 1989; Regenspurg et al. 2015). These geochemical model concepts rest on four foundations (Moog et al. 2015):

- an assumption on the initial composition of the system under consideration,

- an assumption as to the relevant aqueous (or gaseous) species and solid phases,

- a thermodynamic database or parameter file which contains thermodynamic data for all relevant aqueous (and gaseous) species and solid phases, usually conveyed as code-specific formatted parameter file, and

- a suitable code which, upon input of initial system composition and parameter file, calculates its composition at thermodynamic equilibrium.

"The model" is a term which is applied to both the hydrogeochemical concepts and reactions which are implemented to solve the posed questions and the software which implements a numerical solver for the set of thermodynamic equations and the parameter file with the thermodynamic data edited for the specific software code. This parameter file usually contains function parameters to upscale the database to different temperatures and pressures.

In practical terms, a parameter file (and not an underlying database) is usually part of "the model". Along with boundary conditions set for any system under consideration, it imposes substantial assumptions as to speciation, activity corrections, and selected thermodynamic data on all calculations. For users not acquainted with database development, it is usually not possible to assess for which conditions it was optimised and tested. The situation is not improved by the fact that many parameter files are poorly documented and do not state the validity range for temperature functions, where thermodynamic data were obtained from, or whether solubility constants were derived from solubility equilibrium studies or thermochemical data.

As it is almost impossible to test the model codes for all possible applications, the implementation of thermodynamic databases has to adapt to new applications. The exploration and production of deep hydrogeothermal energy is a new application and requires careful checking of the databases and parameter files used in the model.

Some efforts to ease the user with the decision of a database were made in recent years. Such comparisons involving different thermodynamic data and/or models have been performed for calcite (Haase et al. 2013), speciation calculations due to $\mathrm{CO}_{2}$ injection (de Lucia et al. 2012), or for sulphate minerals (Doubra et al. 2017; Zhen-Wu et al. 
2014). Voigt et al. (2018) developed a new parameter file for $\mathrm{CO}_{2}$ storage at elevated temperatures from the core10.dat parameter file (Neveu et al. 2017). Furthermore, the parameter files phreeqc.dat and pitzer.dat were validated for a wide range of minerals and conditions (Appelo 2015; Appelo et al. 2014). Nevertheless, these studies still leave an incomplete picture with regard to widely used model approaches for the solubility of scale-forming minerals at temperatures up to $200^{\circ} \mathrm{C}$, pressures up to $500 \mathrm{bar}$, and $\mathrm{NaCl}$ concentration up to 6 molal.

In this study, we apply some widely used parameter files and model codes on published experimental data which are meaningful for hydrogeothermal applications and assess the reliability of those files. The benchmarking focusses on the solubilities of important matrix and scale-forming minerals (barite, celestite, calcite, siderite, and dolomite). Simulations were performed using the popular geochemical code PHREEQC and the thermochemical programming library ChemApp along with the parameter files slop16.dat, phreeqc.dat, pitzer.dat, and llnl.dat The results were compared to experimental data at relevant pressure, temperature, and salinity conditions.

This study can therefore serve as a documented benchmark for the model code performance and support the selection process of thermodynamic parameter files. Furthermore, user awareness is raised to the fact that each parameter file is valid for a particular range of conditions only which is usually not documented and that they must be checked with experimental data (validation) in order to gain confidence into their credibility if applied to other systems.

\section{Methods}

\section{Definition}

The term "database" needs further explanation here. It is often used in an unclear manner.

In view of the practical requirements necessary to create internally consistent and quality assured parameter files, we propose the following definition: a "database" is a technical framework which ensures that dependent and independent data are stored in a manner which maintains internal consistency when independent data are modified. Examples for databases in this sense are THERMOCHIMIE (Giffaut et al. 2014) or THEREDA (Moog et al. 2015). They constitute secured sources for thermodynamic data from which parameter files can be exported. However, the majority of geochemical calculations are performed using parameter files which are not backed by a database. They are also referred to as "databases" but are actually plain-text ASCII files which contain thermodynamic data in a code-specific format. Such files can easily be shared, modified with usual text editors, and subsequently forwarded to colleagues. If such a file is neither renamed nor documented internally with regard to modifications, it becomes increasingly difficult to judge which version one is working with. Frequently, such files are poorly documented and one can never be sure whether after the addition or modification of data, internal consistency is maintained. For such code-specific files we use the term "parameter file". 


\section{Equations: temperature and pressure dependencies}

Temperature dependence of the solubility constant $\log _{10} \mathrm{~K}$ in PHREEQC is by default implemented as a polynomial correction function with the form:

$$
\log _{10} K=A_{1}+A_{2} T+\frac{A_{3}}{T}+A_{4} \cdot \log _{10} T+\frac{A_{5}}{T^{2}}+A_{6} T^{2},
$$

where $T$ is the temperature and $A_{1}-A_{6}$ parametrise the temperature function and are written in the parameter file. For some entries, no correction parameters $A_{1}-A_{6}$ exist. In that case, usually enthalpy of reaction $\left(\Delta_{r} H\right)$ is given, which can be used for temperature corrections by the following equation, usually referred to as two-term extrapolation:

$$
\log _{10} K=\log _{10} K_{r}+\frac{\Delta_{r} H^{0}}{2.303 \cdot \mathrm{R}} \cdot\left(\frac{1}{T_{r}}-\frac{1}{T}\right),
$$

where $\mathrm{R}$ is the gas constant and $K_{r}, T_{r}$ the equilibrium constant and temperature at reference conditions. However, this approach is best suited for reactions having species with equal charges on both sides ("iso-coulombic reactions") exhibiting a standard molar heat capacity of reaction $\Delta_{r} S^{0}$ and a standard entropy of reaction $\Delta_{r} C_{p}^{0}$ near zero. The application of this approximation should therefore be done with caution, especially for dissolution reactions which involve the hydration of ions.

Pressure dependence in PHREEQC is implemented using a so-called HKF-modifiedRedlich-Rosenfeld (HKFmoRR) equation (Appelo et al. 2014). It is an extension of the expression for standard partial molal volumes from the HKF formalism which is valid at infinite dilution only. In the HKFmoRR equation, additional terms for the ionic strength dependence of partial molal volumes are added. Altogether nine coefficients (five from the original HKF equations and four for the ionic strength dependence) are needed for each aqueous species.

ChemApp on the other hand natively supports the use of the HKF formalism. Thus, the influence of temperature and pressure is implemented accordingly to calculate the corresponding Gibbs energy functions of all aqueous species (for equations, cf. Helgeson et al. 1981; Tanger and Helgeson 1988). For solid phases, standard molar enthalpies of formation, standard molar entropies, and heat capacity functions were used as given in slop16 (http://geopig.asu.edu/sites/default/files/slop16.dat). Thus, the parameter file used for ChemApp is strictly applicable for low-saline solutions only, but features a lot more aqueous species (including complexes) than Pitzer databases usually do.

\section{Databases}

Among the databases available, slop16.dat or previous versions from Helgeson and co-workers are widely used and serve as a quasi-standard in geochemical modelling. Despite the slop database being widely accepted and used, it has to be taken into consideration that many data had been derived from a knowledge base from circa 19702000 and may be outdated by now. In part, data rely on correlation only. This applies especially to high temperature and high pressure conditions, for which fewer experimental data are available than for standard conditions $\left(25^{\circ} \mathrm{C}, 1 \mathrm{bar}\right)$ (cf. Sverjensky et al. 1997). Almost all thermodynamic data which are currently used in hydrogeochemical codes rely to some extent on this database. The data listed in slop16.dat allow for the 
calculation of p,T-dependent Gibbs energies of formation of aqueous species and solid phases. For law of mass action codes, these data need to be transformed into equilibrium constants using numerical tools like SUPCRT92 (Johnson et al. 1992) or CHNOSZ (Dick 2008). Examples where many parameter file entries are derived from slop data are (to name only a few): llnl.dat (PHREEQC), thermo_pitzer.tdat (Geochemist's Workbench) (Bethke 2007), or data0.ypf (EQ3/6) (Wolery 1992). Gibbs energy minimization (GEM) codes such as ChemApp (Petersen and Hack 2007) or GEM-Selector (Kulik et al. 2013) can make direct use of the thermodynamic data from slop, using the revised Helgeson-Kirkham-Flowers (HKF) formalism (Helgeson et al. 1981; Tanger and Helgeson 1988). However, it must be kept in mind that the speciation model implemented in the aforementioned parameter files is not necessarily identical to the one in the original HKF-database slop16. The same thermodynamic data (for instance solubility constants calculated from Gibbs free energies of reaction) transferred to a parameter file implementing a different speciation scheme invariably lead to different calculational results. For this reason, it is an interesting exercise to benchmark a parameter file created from the original slop16.dat.

Thermodynamic databases contain thermodynamic properties at standard state conditions (e.g. infinite dilution) and at reference temperature and pressure (e.g. $25^{\circ} \mathrm{C}$ and 1 bar). The model parameters used for extrapolating thermodynamic data (e.g. $\log _{10} \mathrm{~K}$ ) at elevated temperature, pressure, and salinity are typically derived from regression of experimental data. Examples for this procedure are parameter estimation for pressure dependence (Appelo et al. 2014) or Pitzer parameters (Appelo 2015), statistical machine learning algorithms for fitting barite and celestite solubility (Safari et al. 2014a, b) or global optimisation of Gibbs energies (Miron et al. 2015, 2016, 2017). Thermodynamic data files, which are in active development, will sooner or later see an adjustment, taking into account newly available thermodynamic data. However, this process is not always comprehensively documented for the end user, making it difficult to judge the state of currently distributed thermodynamic data.

The evolution of some of the most important parameter files for hydrogeochemical modelling in geothermal systems is shown in Fig. 1. The influence of slop16 is illustrated because it is of major importance for an understanding of possible error transmission in hydrogeochemical parameter files. This figure is by no means exhaustive and does not express an assessment of the authors concerning parameter files in the figure. Dashed arrows express only little influence, while solid arrows stand for large influence. As can be seen, most of the parameter files used rely to a large extent on data from the Helgeson working group (slop data). The two numerals behind slop indicate the year when this version of the database was released. Native PHREEQC parameter files (phreeqc. dat and pitzer.dat) represent an exception here because they only adopt partial molal volumes for aqueous species at infinite dilution from HKF and extend them to higher salinities applying a model approach proposed by Appelo (2015). The origin of the thermodynamic data in those two files is not documented.

In the present work, four different parameter files are used for direct benchmarking calculations: slop16.dat, phreeqc.dat, pitzer.dat, and llnl.dat. In order to make slop16. dat usable for ChemApp (the Gibbs Energy Minimization code), it had to be reformatted (data structure and cal to J conversion). Among the parameter files available 


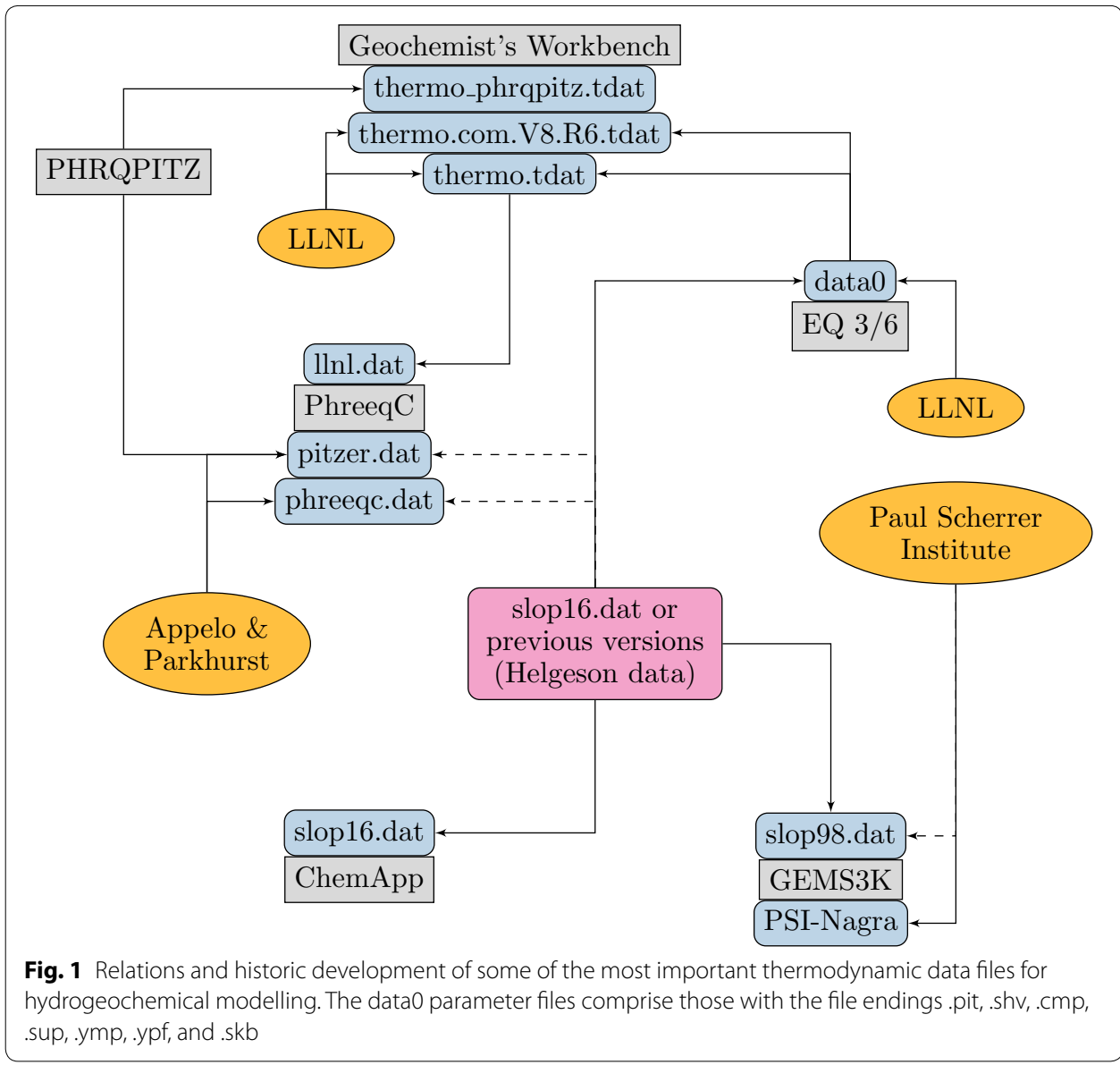

from PHREEQC, phreeqc.dat and pitzer.dat were recently updated for geothermal purposes (Appelo 2015; Appelo et al. 2014). Benchmark calculations for anhydrite, gypsum, silica, barite, calcite, and some salts are provided in the appendix of ditto. Furthermore, llnl.dat was selected for representing the LLNL (Lawrence Livermore National Laboratory) family of parameter files, as it is a translation of a Geochemist's Workbench GWB parameter file (thermo.com.V8.R6.230) into PHREEQC format.

To present an overview for the parameter files used in the present study, we summed up the source of thermodynamic data, the activity model associated with each database, and the formalism for pressure and temperature dependence in Table 1. As shown in the table, Pitzer equations (Pitzer 1973) have a much higher ionic strength limit than the Davies equation (Davies 1938) or the extended Debye-Hückel equation (Debye and Hückel 1923; Helgeson et al. 1981) and are thus better suited for highly saline solutions. The authors acknowledge the fact that the extended Debye-Hückel equation might be valid to relatively high ionic strength when ion-specific parameters were fitted from mean-salt activity-coefficient data. However, this imposes the responsibility to the user to check whether the system composition is covered by the range of validity for the Debye-Hückel equation.

Different activity models and differing pressure and temperature dependencies can lead to divergence in calculation results. The reasons for this are due to the fact that solubility is calculated by the activity of the mineral's compounds in the solution and 
Table 1 Summary of model approaches used in the present work

\begin{tabular}{|c|c|c|c|c|}
\hline \multirow{2}{*}{$\frac{\text { Code }}{\text { Parameter file }}$} & \multicolumn{3}{|l|}{ PHREEQC } & \multirow{2}{*}{$\begin{array}{l}\text { ChemApp } \\
\text { slop16.dat }\end{array}$} \\
\hline & phreeqc.dat & Ilnl.dat & pitzer.dat & \\
\hline $\begin{array}{l}\text { Source of thermodynamic } \\
\text { data }\end{array}$ & Unknown & Mainly: slop & Unknown & slop16 \\
\hline Activity model & \multicolumn{2}{|c|}{ Extended Debye-Hückel equation } & Pitzer equations & Davies equation \\
\hline $\begin{array}{l}\text { Approx. ionic strength } \\
\text { limits of the activity model } \\
(\mathrm{mol} / \mathrm{kg})\end{array}$ & $0.1-3^{\mathrm{a}}$ & $0.1-3^{\mathrm{a}}$ & $6^{a}$ & $0.1-0.5^{\mathrm{a}}$ \\
\hline Pressure dependence & HKFmoRR & None & HKFmoRR & HKF \\
\hline Temperature dependence & \multicolumn{3}{|c|}{$\begin{array}{l}\text { Fitted polynomial equation or two-term extrapolation [cf. } \\
\text { Eqs. (1) and (2)] }\end{array}$} & HKF \\
\hline
\end{tabular}

a Depending on system composition

by the $\log _{10} K$, which is altered at pressures and temperatures differing from $25^{\circ} \mathrm{C}$ and 1 bar.

\section{Solubility data used for validation of the parameter files}

The following tables summarise literature data of solubility for celestite $\left(\mathrm{SrSO}_{4}\right)$, barite $\left(\mathrm{BaSO}_{4}\right)$, calcite $\left(\mathrm{CaCO}_{3}\right),\left(\mathrm{FeCO}_{3}\right)$, and dolomite $\mathrm{CaMg}\left(\mathrm{CO}_{3}\right)_{2}$. None of these tables is an exhaustive literature study, but specific focus was put on available high temperature, high pressure, and high salinity data. We therefore selected some key experimental studies which we used for the validation. Especially for solubility in $\mathrm{KCl}, \mathrm{CaCl}_{2}$, and $\mathrm{MgCl}_{2}$, additional experimental data are available as in the reviews of e.g. Monnin and Galinier (1988) and Visscher and Vanderdeelen (2012). Many of the data not used in this study may be correct, but due to different combinations of composition space, pressure, and temperature conditions, it was not possible to show these data in the following graphs of this study. Data which had been rejected in previous studies or showed major deviations were excluded. Sampling conditions do not always fit into tables, so if ranges are given, only some intermediate values might have been measured by the authors. Where necessary, conversion to molality was done. For conversions, the temperature-dependent density of pure water was calculated from Wagner and Pruß (2002) and of electrolyte solutions with PHREEQC using pitzer.dat.

\section{Celestite (Table 2)}

The data of Müller (1960) show solubilities consistently too high at $\mathrm{NaCl}$ molalities above 1, (cf. Monnin and Galinier 1988, Fig. 6) and were therefore excluded from the present study.

\section{Barite (Table 3)}

Solubility data for high pressure conditions were recently extended by the study of Shi et al. (2012), but the results are displayed as graphs, not as tables. The values are stated in the text only for $483 \mathrm{bar}$, which is why high pressure calculations were only performed at this specific pressure condition. 
Table 2 Solubility data for celestite $\left(\mathrm{SrSO}_{4}\right)$, which was used for comparison with calculated solubility in the present study

\begin{tabular}{lllll}
\hline Author & Year & $\boldsymbol{T}\left({ }^{\circ} \mathbf{C}\right)$ & $\boldsymbol{p ( b a r )}$ & $\begin{array}{l}\mathbf{N a C l} \\
(\mathbf{m o l} / \mathbf{k g})\end{array}$ \\
\hline Culberson et al. & & 25 & 1.013 & $0-0.7$ \\
Davis and Collins & 1978 & 25 & 1.013 & $0.01-2$ \\
Howell et al. & 1971 & $25-250$ & $1-500$ & $0.5-4$ \\
Lucchesi and Whitney & 1992 & 0,25 & 1.013 & $0.01-5.6$ \\
Reardon and Armstrong & 1962 & $10-89.3$ & 1.013 & $0-5$ \\
Strübel & 1987 & $22-100.5$ & 1.013 & $0.1-2.3$ \\
Vetter and Vandenbroek & 1966 & $25-125$ & 1.013 & $0-5.7$ \\
\hline
\end{tabular}

Table 3 Solubility data for barite $\left(\mathrm{BaSO}_{4}\right)$, which was used for comparison with calculated solubility in the present study

\begin{tabular}{lllll}
\hline Author & Year & $\boldsymbol{T}\left({ }^{\circ} \mathbf{C}\right)$ & $\boldsymbol{p}$ (bar) & $\begin{array}{l}\mathbf{N a C l} \\
(\mathbf{m o l} / \mathbf{k g})\end{array}$ \\
\hline Blount & 1977 & $22-280$ & $1-1400$ & $0,0.2,4$ \\
Melcher & 1910 & $18-100$ & 1.013 & 0 \\
Shi et al. & 2012 & $25-250$ & $34.5-1517$ & $0-6$ \\
Strübel & 1967 & $20-600$ & $1.013-2000$ & $0-2.08$ \\
Templeton & 1960 & $25-95$ & 1.013 & $0-5$ \\
Uchameyshvili & 1966 & $95-370$ & $1.013-208$ & $0.25-2.08$ \\
\hline
\end{tabular}

Table 4 Solubility data for calcite $\left(\mathrm{CaCO}_{3}\right)$, which was used for comparison with calculated solubility in the present study [modified from Coto et al. (2012)]

\begin{tabular}{lllll}
\hline Author & Year & $\boldsymbol{T}\left({ }^{\circ} \mathbf{C}\right)$ & $\boldsymbol{p}\left(\mathbf{C O}_{2}\right)$ (bar) & $\begin{array}{c}\mathbf{N a C l} \\
(\mathbf{m o l} / \mathbf{k g})\end{array}$ \\
\hline Ellis & & $100-300$ & $2-150$ & $0.2-1$ \\
McCoy and Smith & 1963 & 25 & $0.1-25.4$ & 0 \\
Miller & 1911 & $0-105$ & $1-100$ & $0-0.5$ \\
Mitchell & 1952 & 25 & $1-24$ & 0 \\
Nakayama & 1923 & 25 & $0.01-1$ & 0 \\
Segnit et al. & 1968 & $75-200$ & $1-60$ & 0 \\
Shi et al. & 1962 & $0-250$ & $34.5-1448^{\mathrm{a}}$ & $0.1,4$ \\
Wolf et al. & 2013 & $10-60$ & 0.01 & $0-6$ \\
\hline
\end{tabular}

a System pressure instead of $p\left(\mathrm{CO}_{2}\right)$

\section{Calcite (Table 4)}

Calcite solubility literature data for a broad range of temperatures, pressures, and ionic strengths are summarised in Table 4. Existing data for boundary conditions relevant in geothermal facilities are limited to the few sources reporting solubilities for pressures above several bar and temperatures above $50{ }^{\circ} \mathrm{C}$. Calcite solubilities reported by Miller (1952) for pressures exceeding 10 bar are low compared to Ellis (1963) and Segnit et al. (1962). The latter tried to reproduce data in Miller (1952) with the same experimental setup but failed. Furthermore, the data were rejected in the IUPAC-NIST solubility data series compilation because solubilities of Miller (1952) at 
1 bar $\mathrm{CO}_{2}$ partial pressure and "in the mid-range of the temperatures tested were too low" (Visscher and Vanderdeelen 2012, p. 27). Data from Miller (1952) have therefore only been included in the upper $10 \%$ of temperatures $\left(98-102{ }^{\circ} \mathrm{C}\right)$ measured therein due to the lack of experimental data for high $\mathrm{CO}_{2}$ partial pressures, but should nevertheless be regarded with care.

For the solubility of calcite at $\mathrm{CO}_{2}$ partial pressures in the range 1.5-10 bar, only data from Mitchell (1923) were found. This partial pressure region is of great interest for geothermal problems, as it constitutes the conditions encountered in many reservoirs. In the meta-analysis of calcite solubility from (Visscher and Vanderdeelen 2012; Visscher et al. 2012), they fitted two models through all of the available calcite solubility data. Model 2 from this study uses Pitzer equations (Visscher et al. 2012). The deviation between model 2 and Mitchell (1923) data was very high with up to $12.5 \%$ (at 4 bar $\mathrm{CO}_{2}$ partial pressure). The other data points from Mitchell (1923) fit within an margin of error of $4.2 \%$ and therefore are more credible. As a consequence, we decided to include the data from the fit of model 2 (Visscher and Vanderdeelen 2012; Visscher et al. 2012) in order to account for possible experimental uncertainty.

\section{Siderite (Table 5)}

Silva et al. (2002) provide a detailed study on solubility in $\mathrm{NaCl}$ solutions up to 5.5 molal, but experimental accuracy is probably hampered by the difficulty of measuring pH values in brines. Bruno et al. (1992) measured siderite solubility in acid and alkaline solutions and provide the only comprehensive dataset to study the formation of complexes at $\mathrm{pH}>7$. However, the equilibration time of 3 days is probably too low, as pointed out by Bénézeth et al. (2009), who report equilibrium after about 18 days for temperatures of $25^{\circ} \mathrm{C}$. We did not use data from Yan et al. (2015), who allowed equilibration for only between 0.5 and $3 \mathrm{~h}$ in their experiments. Conversely to other publications of this research group, which used the same experimental setup (Shi et al. 2012, 2013), it is not specified how they tested if equilibrium was indeed attained. However, Yan et al. (2015) measured solubility at temperatures exceeding $150{ }^{\circ} \mathrm{C}$ and 334 bar. At higher temperatures, equilibrium with siderite is attained more quickly than at e.g. $25{ }^{\circ} \mathrm{C}$. For temperatures exceeding $100{ }^{\circ} \mathrm{C}$, Bénézeth et al. (2018) report equilibration times below $24 \mathrm{~h}$, which is in accordance with the higher dissolution rate measured by (Golubev et al. 2009) at $100{ }^{\circ} \mathrm{C}$ compared to $25{ }^{\circ} \mathrm{C}$. Therefore, it seems generally possible that equilibrium was reached in the experiments of Yan et al. (2015); however, equilibration times still appear low.

\begin{tabular}{|c|c|c|c|c|}
\hline Author & Year & $T\left({ }^{\circ} \mathrm{C}\right)$ & $p$ (bar) & $\begin{array}{l}\mathrm{NaCl} \\
(\mathrm{mol} / \mathrm{kg})\end{array}$ \\
\hline Bénézeth and Dandurand & 2009 & $25-250$ & $10-48.5$ & 0.1 \\
\hline Bruno et al. & 1992 & 25 & 1.013 & 0 \\
\hline Silva et al. & 2002 & 25 & 1.013 & $0.1-5.5$ \\
\hline
\end{tabular}




\section{Numerical methods}

PHREEQC

PHREEQC is a computer program designed to perform a wide variety of aqueous geochemical calculations (Parkhurst and Appelo 2013). For the present work, version 3.3.11 was used from subversion 12535-12702 (Parkhurst 2017) using Windows 10 as operating system. The parameter files pitzer.dat, phreeqc.dat, and llnl.dat were taken as included in those PHREEQC subversions.

\section{ChemApp}

ChemApp is a programming library for performing thermochemical calculations by minimising total Gibbs energy of the system (Petersen and Hack 2007). It is commercially available from GTT Technologies. Thermochemical calculations can be executed by a set of subroutines used for chemical equilibrium calculations. In the present work, the revised Helgeson-Kirkham-Flowers formalism for infinite dilution and the revised HKF formalism in combination with the Davies equation (Davies 1938) was used. Generally, also the use of the Pitzer formalism is possible with ChemApp. However, for the present work, no suitable parameter file was available.

ChemApp has its origin in metallurgical applications and is usually applied for conditions when liquid water is not stable. However, a small user community also uses it for calculations related to aqueous equilibrium chemistry. Its usage for this work was due to the special interest of the authors in its applicability for geothermal systems. A different geochemical modelling software that can be used to model geochemical systems is GEM-Selector. The code package uses GEMS3K for doing Gibbs energy minimization (Kulik et al. 2013) and has access to a suite of solution models through the TsolMod library (Wagner et al. 2012). However, testing of this code was beyond the scope of the present work.

\section{$R$ and CHNOSZ}

The $\mathrm{R}$ programming language and environment for statistical computing and graphics ( $R$ core team 2017) was used to write the script which translates the slop16 database into a ChemApp readable parameter file. Version 3.3.3 (codename "Another Canoe") was used. Calculations of thermodynamic properties from the slop database using the revised Helgeson-Kirkham-Flowers formalism were done with version 1.1.0 of the package CHNOSZ (Dick 2008), an integrated set of tools for thermodynamic calculations in geochemistry and compositional biology. This package implements the revised HKF formalism as in SUPCRT92 (Johnson et al. 1992). Thermodynamic properties calculated from CHNOSZ are comparable to SUPCRT92, as they both implement the same version of the HKF formalism.

\section{Results and discussion}

\section{Celestite}

Experimental data for celestite were recalculated in pure water and in $\mathrm{NaCl}$ solutions. At first, calculations were performed in pure water with varying temperature and at 1 bar pressure below $100^{\circ} \mathrm{C}$ and at saturation vapour pressure above $100^{\circ} \mathrm{C}$ (Fig. 2). Both, phreeqc.dat and pitzer.dat, are able to reproduce the experimental 


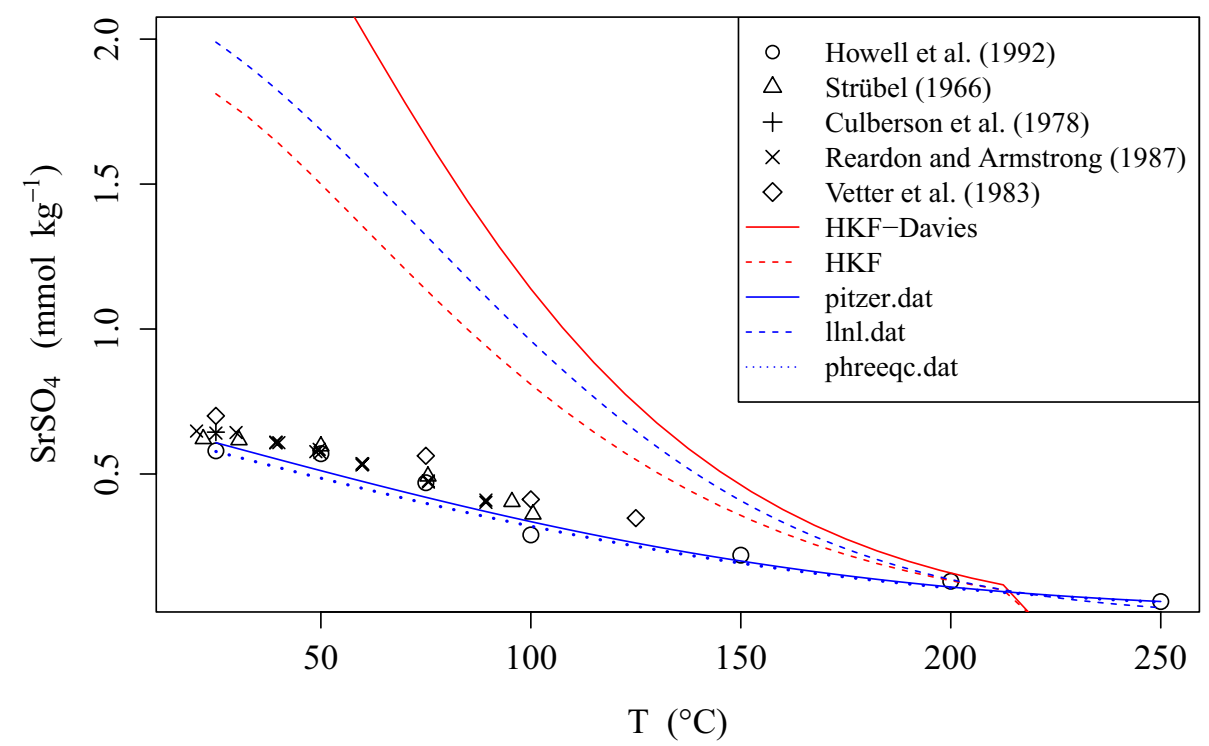

Fig. 2 Solubility of celestite in pure water at 1 bar pressure below $100{ }^{\circ} \mathrm{C}$ and at saturation vapour pressure above $100^{\circ} \mathrm{C}$

data. It seems as if they were regressed on the experimental data of Howell et al. (1992), mainly because at temperatures below $100^{\circ} \mathrm{C}$, most other experimental values are by about 0.04-0.07 mmol higher. HKF and HKF-Davies shown in Fig. 2 and the following figures abbreviate the HKF approach for infinite dilution and the HKF approach for infinite dilution combined with the Davies equation. Above about 220 ${ }^{\circ} \mathrm{C}$, the calculations with ChemApp (HKF and HKF-Davies) had convergence problems, which result in the kink of the plot at that temperature. The convergence problem only occurred for this specific calculation. No stability issues were encountered for other calculations. The reason for the difference between the two models can be attributed to the fact that no activity model is used in the HKF approach for infinite dilution. All models based on thermodynamic data from Helgeson et al. show solubilities which are significantly too high (up to 4 times) at temperatures below $200{ }^{\circ} \mathrm{C}$. In order to assess the reason for this discrepancy, $\log _{10} \mathrm{~K}$ values for the reaction $\mathrm{SrSO}_{4} \rightleftharpoons \mathrm{Sr}^{2+}+\mathrm{SO}_{4}{ }^{2-}$ were calculated from CHNOSZ for standard conditions (298.15 K and 1 bar) and compared to phreeqc.dat, pitzer.dat, and literature data. In CHNOSZ, slop16.dat and llnl.dat, $\log _{10} \mathrm{~K}$ for celestite is -5.68 compared to -6.67 in phreeqc.dat and pitzer.dat. This implies that the equilibrium constant in slop16. dat and llnl.dat favours the solid phase in the reaction more than phreeqc.dat and pitzer.dat do, resulting in higher solubilities. The strontium speciation in the model shows the formation of strontium complexes which occur in concentration by orders of magnitude lower than aqueous $\mathrm{Sr}^{2+}$. Therefore, it is not the speciation model leading to the deviation from solubility data.

In slop16.dat, Helgeson et al. (1978) is stated as the source for the $\log _{10} \mathrm{~K}$, but therein, no original source for the thermodynamic data is given. Gibbs free energies and formation enthalpies for minerals were regressed by Helgeson et al. (1978) using standard molal entropies, heat capacities, and volumes derived from calorimetric, crystallographic, and density data or estimations from correlation algorithms and Clapeyron 
slope constraints. To the authors' knowledge, the first comprehensive study of thermodynamic properties from reaction equilibration of celestite was carried out by Reardon and Armstrong (1987), who suggest that thermodynamic data for celestite prior to their study may have been corrupted due to experiments which did not finally attain equilibrium. The $\log _{10} \mathrm{~K}$ value they established is -6.67 and is probably the source of phreeqc. dat and pitzer.dat. As a consequence, it seems possible that the thermodynamic data compiled by Helgeson et al. (1978) do not represent the current state of knowledge for celestite and corrections concerning thermodynamic properties have to be made therein.

Furthermore, a comparison with experimental data is shown in up to 6 molal $\mathrm{NaCl}$ solution (Fig. 3). Models based on thermodynamic data from Helgeson and co-workers (slop16.dat) perform poorly again, even at ionic strength's lower than 0.5 molal where the Davies equation would still be valid (Stumm and Morgan 1996). Initial solubilities at ionic strengths below 0.1 significantly deviate from experimental data due to the too high $\log _{10} \mathrm{~K}$ value. As expected, phreeqc.dat is not able to describe the solubility at very high ionic strengths, but provides remarkably good results. At ionic strengths above 3 molal, experimental data are scarce; however, the available data can be nicely reproduced with pitzer.dat.

In some of the EQ3/6 parameter files, the $\log _{10} \mathrm{~K}$ value was taken directly from SUPCRT92 (data0.ymp), while in others it was partially corrected (data0.ypf). Corrections of the latter were an adoption of the $\log _{10} \mathrm{~K}$ of celestite to -6.63 at $25^{\circ} \mathrm{C}$; however, the temperature grid was not adapted, resulting in a $\log _{10} \mathrm{~K}$ of 500 at any temperature other than $25{ }^{\circ} \mathrm{C}$ which is read as "no data" by EQ3/6. Geochemist's Workbench parameter files are also only partially corrected. The parameter file thermo.tdat has a $\log _{10} \mathrm{~K}$ entry of -6.43 at $25^{\circ} \mathrm{C}$, which is close to the value of -6.67 from (Reardon and Armstrong 1987). Conversely, thermo.com.V8.R6+.tdat operates with a $\log _{10} \mathrm{~K}$ value of -5.68 for celestite, which is comparable with the value from llnl.dat.

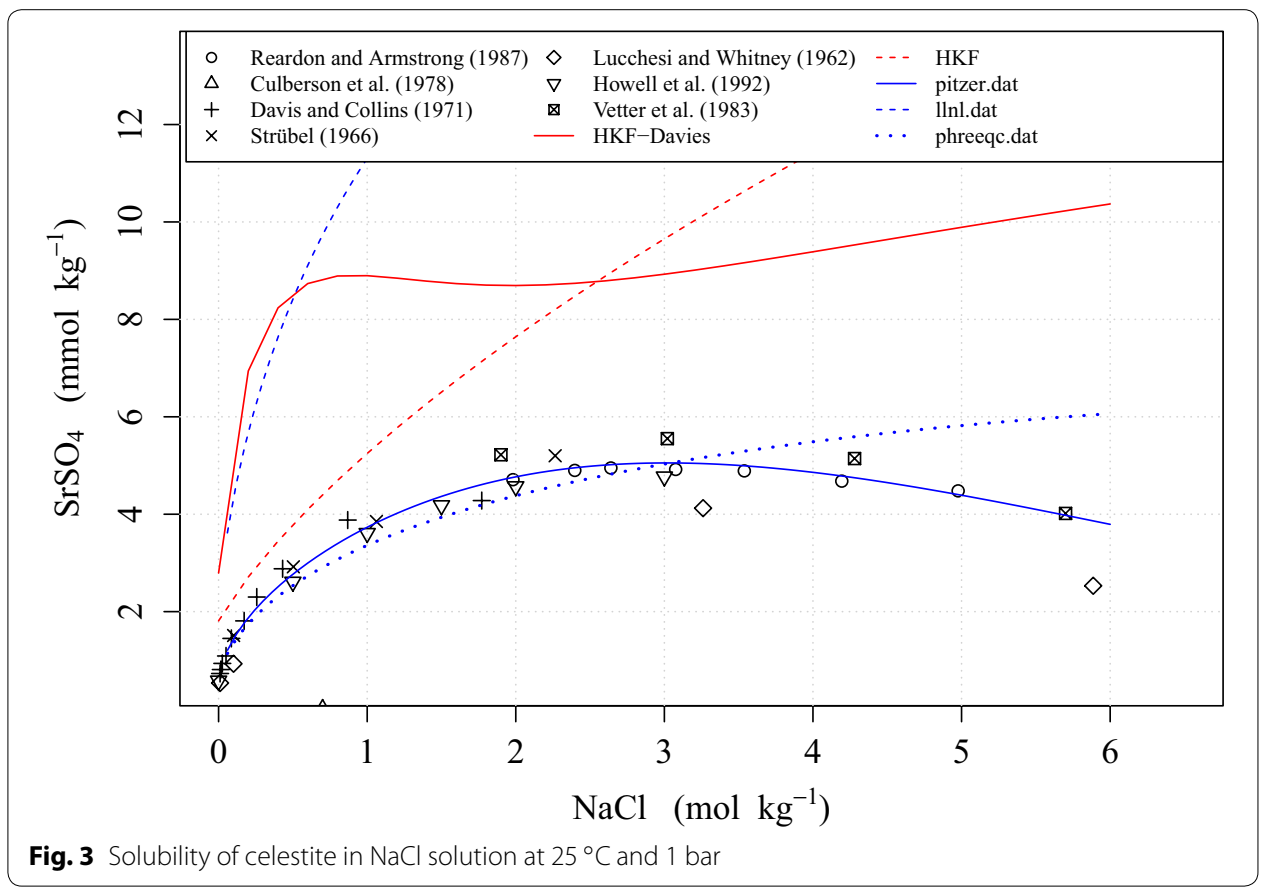




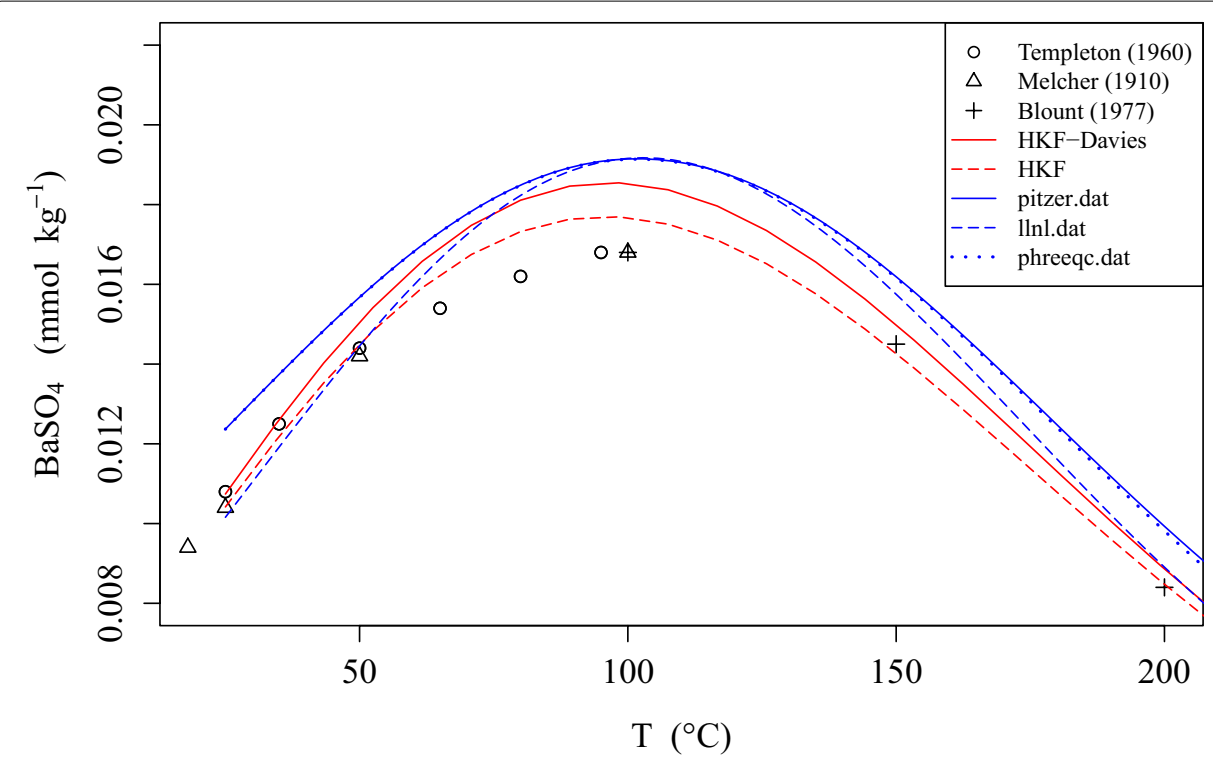

Fig. 4 Solubility of barite in pure water at 1 bar pressure below $100^{\circ} \mathrm{C}$ and at saturation vapour pressure above $100^{\circ} \mathrm{C}$

\section{Barite}

Barite solubility was calculated for pure water as a function of temperature (Fig. 4). All models seem to provide a reasonably good description of the solubility; however, the HKF models provide a better agreement with experimental data in the range of $80-150{ }^{\circ} \mathrm{C}$. Nonetheless, the HKF models still overestimate solubility in this range. The error at $100{ }^{\circ} \mathrm{C}$ for $\mathrm{HKF}$ is $9 \mathrm{e}-4 \mathrm{mmol} / 5.3 \%$, and $1.7 \mathrm{e}-3 \mathrm{mmol} / 10.4 \%$ for the HKFDavies model. The PHREEQC models deviate by $2.3 \mathrm{e}-3 \mathrm{mmol} / 13.7 \%$ each.

To represent conditions in deep geothermal reservoirs, a comparison with experimental data was done for pressures up to 500 bar (Fig. 5). The solubility interpolated from Blount (1977) is adequately described by phreeqc.dat and pitzer.dat, but both parameter files deviate from experimental data by Shi et al. (2012) at temperatures above $200{ }^{\circ} \mathrm{C}$. Calculations with llnl.dat are consistently too low, which is most likely due to the missing pressure correction of $\log _{10} \mathrm{~K}$ in llnl.dat. Note that the upper pressure limit for calculations with thermo.com.V8.R6.230, the parameter file llnl.dat was derived from, is about 86 bar. Among the models based on slop16.dat only HKF-Davies is able to describe the solubility up to about $100{ }^{\circ} \mathrm{C}$, while the HKF model for infinite dilution completely fails due to the ionic strength of 0.1 molal. Above $100{ }^{\circ} \mathrm{C}$, significant amounts of $\mathrm{BaCl}^{+}$are formed using slop16 with ChemApp (red lines), but not in llnl.dat. The formation of the barium complex can be related to the fact that about $85^{\circ} \mathrm{C}$, the reaction $\mathrm{BaCl}^{+} \rightleftharpoons \mathrm{Ba}^{2+}+\mathrm{Cl}^{-}$shows positive $\Delta_{r} G$ (cf. Fig. 6) which means that the reaction proceeds spontaneously in the reverse direction forming $\mathrm{BaCl}^{+}$. As $\Delta_{r} G$ becomes more positive at higher temperatures, increasing amounts of $\mathrm{BaCl}^{+}$occur in the model causing a higher calculated solubility of barite. Comparison of the thermodynamic data with llnl.dat yields the same $\log _{10} \mathrm{~K}$ of -0.4977 , but different $\Delta_{r} H^{0}(\operatorname{llnl}: 11.142 \mathrm{~kJ} / \mathrm{mol}$; CHNOSZ: $13.012 \mathrm{~kJ} / \mathrm{mol}$ ) and slightly different standard state enthalpy of formation $\Delta_{f} H^{0}$ (llnl: $-693.58 \mathrm{~kJ} / \mathrm{mol}$; slop16: $\left.-691.70 \mathrm{~kJ} / \mathrm{mol}\right)$. The difference in thermodynamic 


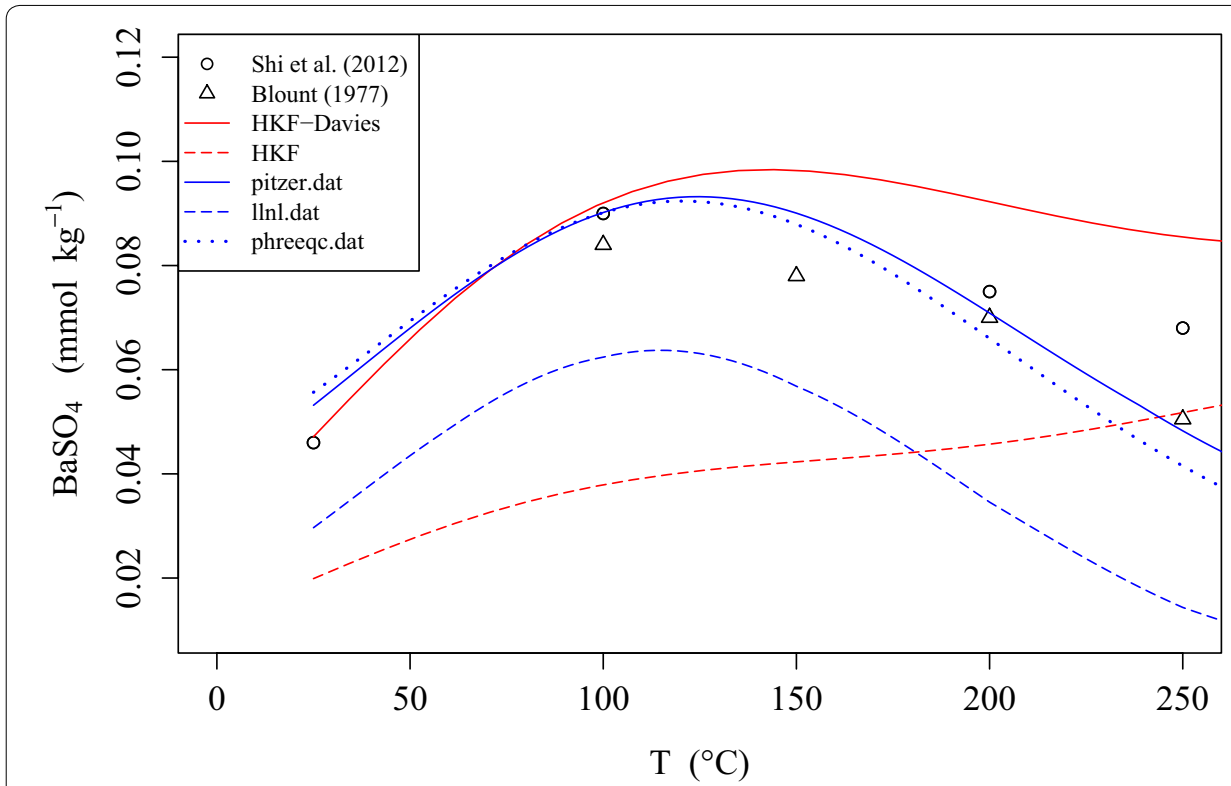

Fig. 5 Solubility of barite in 0.1 molal $\mathrm{NaCl}$ solution at 483 bar (Shi et al. 2012) and at 500 bar (interpolated by Blount 1977)

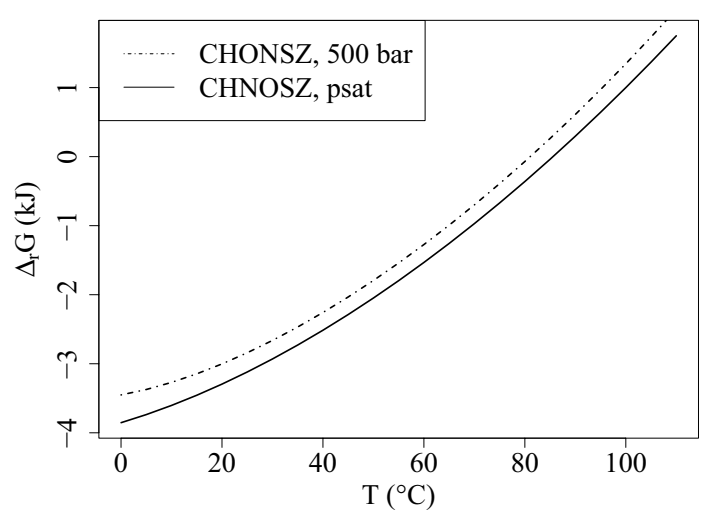

Fig. 6 Gibbs energy of reaction $\left(\Delta_{r} G\right)$ for $\mathrm{BaCl}^{+} \rightleftharpoons \mathrm{Ba}^{2+}+\mathrm{Cl}^{-}$

data is not the reason why llnl.dat does not form $\mathrm{BaCl}^{+}$, as lower $\Delta_{r} H^{0}$ would result in the formation of the complex at lower temperatures. As the tendency to form the $\mathrm{BaCl}^{+}$ complex increases with increasing pressure (cf. Fig. 6), the missing pressure correction in llnl.dat is probably the reason why this complex does not occur in the llnl.dat simulation.

Thermodynamic data in the HKF database (slop16.dat) for chloride complexes were taken from Sverjensky et al. (1997) who obtained thermodynamic data (standard partial molal properties) by regression of literature reported dissociation constants $\beta$. The problem with the $\mathrm{BaCl}^{+}$data is that literature data for regression (Majer and Stulik 1982) is only available for temperatures up to $85^{\circ} \mathrm{C}$ (cf. Fig. 7) which is precisely where the barium complex is formed at significant amounts in the model for 500 bar pressure.

The dissociation constant of $\mathrm{BaCl}^{+}$is shown in Fig. 7 at a pressure of 1 bar and at water vapour saturation pressure above $100{ }^{\circ} \mathrm{C}$. At these pressure conditions, the 
spontaneous formation of $\mathrm{BaCl}^{+}$would proceed at a temperature of about $5 \mathrm{~K}$ less than for pressures of 500 bar. Furthermore, for $\mathrm{BaCl}^{+}$and $\mathrm{SrCl}^{+}$, Sverjensky et al. (1997) point out the "substantial uncertainty deriving experimental $\log _{10} \mathrm{~K}$ values when the latter range (sic) from about 0 to +1.0 ". Consequently, thermodynamic data for the two chloride complexes are not based on sound experimental data. It has been recently shown by Miron et al. (2017) that if new experimental data for complexes are available, the $\log _{10} \mathrm{~K}$ values need to be refined. To give some examples: Differences in logarithmic association constants between slop16.dat data and regression on new experimental data can be as high as $3\left(\right.$ for $\left.\mathrm{CaCl}_{2}^{0}\right), 1.5\left(\right.$ for $\left.\mathrm{CaCl}^{+}\right)$, or $1\left(\right.$ for $\left.\mathrm{MgCl}^{+}\right)$at pressure and temperature conditions comparable to the experimental data used for recalculations. In the case of $\mathrm{CaCl}^{+}$and $\mathrm{MgCl}^{+}$, the original $\log _{10} \mathrm{~K}$ values (Sverjensky et al. 1997) were based on data from Majer and Stulik (1982) which is also the source for $\mathrm{BaCl}^{+}$. As a consequence, the occurrence of these complexes at temperatures above $85{ }^{\circ} \mathrm{C}$ is doubtful and probably the source of error for the elevated concentration in the HKF-Davies model at high temperature, high pressure calculations. This example illustrates that apparently sound and well-established thermodynamic data (in this case $\log _{10} \beta$ for $\mathrm{BaCl}^{+}$) are in fact ill-defined by insufficient experimental data. It further exemplifies that the selected speciation model has a profound impact on the calculated results. When changing a speciation model in thermodynamic databases or parameter files, consistency has to be maintained. This applies especially to thermodynamic data originating from different sources. It is not sufficient to simply include a new species, even if it is based on sound thermodynamic data, without adapting the whole speciation model.

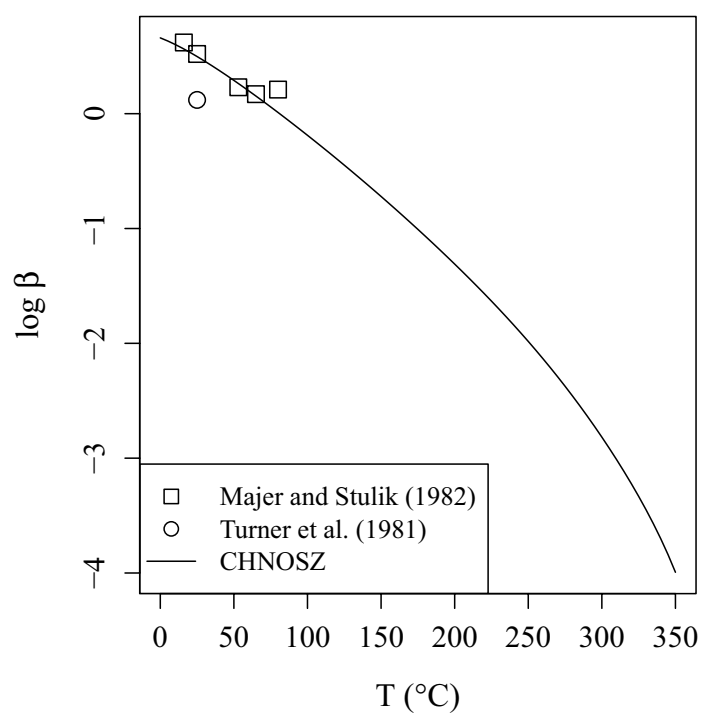

Fig. 7 Logarithm of the dissociation constant of $\mathrm{BaCl}^{+} \rightleftharpoons \mathrm{Ba}^{2+}+\mathrm{Cl}^{-}$ 


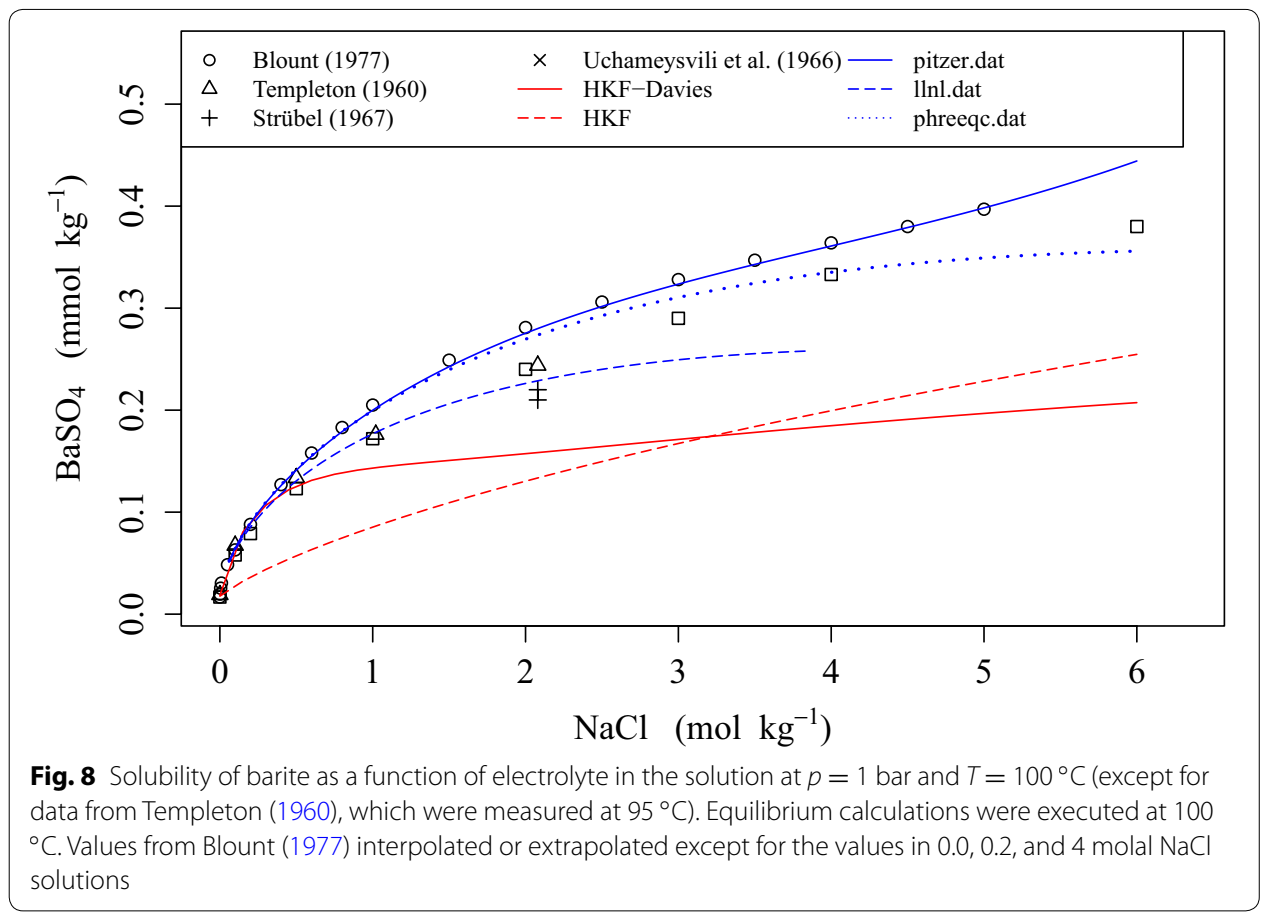

Recalculation of the solubility as a function of $\mathrm{NaCl}$ concentration is shown in Fig. 8. Not surprisingly, the HKF approach for infinite dilution quickly deviates from experimental data due to the ionic strength exceeding the limit of applicability for this approach. As a consequence, we decided not to include the HKF approach for infinite dilution without activity correction in the following calculations, as it is not considered a promising approach for even slightly saline solutions. This was however expected due to the ionic strength limit of 0.001 (Eriksson and Petersen 2013). Both llnl.dat and HKFDavies provide good results up to about 0.5 molal $\mathrm{NaCl}$ solutions, where the limits for the activity correction models are exceeded. The phreeqc.dat database-as in high salinity data for celestite (cf. Fig. 3) - works remarkably well up to a $\mathrm{NaCl}$ molality of about 3 , which seems to be the limit for the extended Debye-Hückel equation with fitted b-dot parameters. The parameter file pitzer.dat provides a near perfect agreement with the data from Templeton (1960), but overestimates data from Blount (1977). Given the fact that most of the data from Blount (1977) were extrapolated, the data from Templeton are given more credibility. 


\section{Calcite}

Calcite is a major scale-forming mineral and of great importance for geothermal fluids which were in contact with calcareous reservoir material. Due to the calco-carbonic equilibrium, the solubility behaviour is relatively complex. Calcite solubility depends on temperature, pressure, $\mathrm{CO}_{2}$ partial pressure, $\mathrm{pH}$, and ionic strength. During production of geothermal fluids, a change in temperature, pressure, and gas load (in case of degassing) occurs.

For the evaluation of the solubility of calcite dependent on $\mathrm{CO}_{2}$ partial pressure, solubility data at a temperature of $100{ }^{\circ} \mathrm{C}$ as a function of $\mathrm{CO}_{2}$ partial pressure were recalculated (Fig. 9). There exist only few data for calcite at pressures significantly above atmospheric pressure so data from Miller were included, although they are probably too low at higher partial pressure due to experimental issues (cf. section on solubility data). The HKF-Davies approach provides the best model performance although solubility is slightly overestimated at higher partial pressures. At partial pressures above 20 bar, the calculations with llnl.dat and phreeqc.dat parameter files significantly exceed the experimental data, while pitzer.dat falls below the data from Segnit (1962). This can be attributed to the formation of the $\mathrm{CaHCO}_{3}{ }^{+}$complex in phreeqc.dat and llnl.dat.

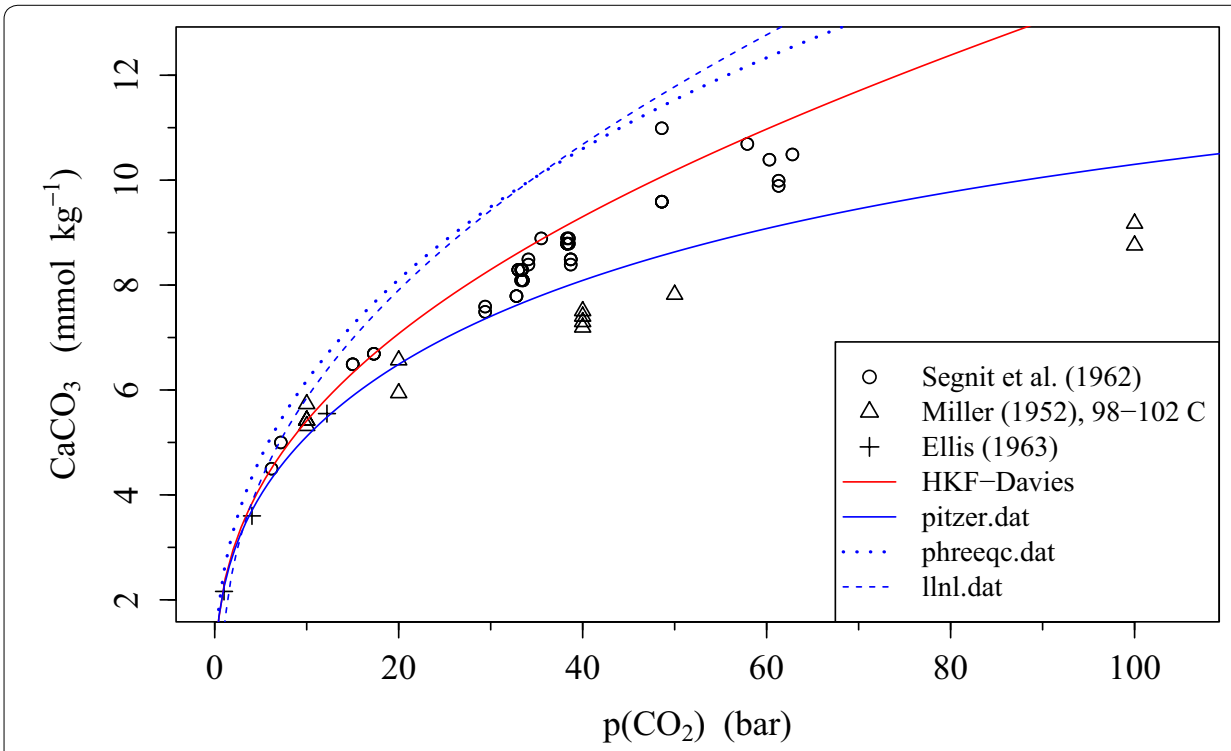

Fig. 9 Solubility of calcite as a function of $p\left(\mathrm{CO}_{2}\right)$ with $T=100^{\circ} \mathrm{C}$ 


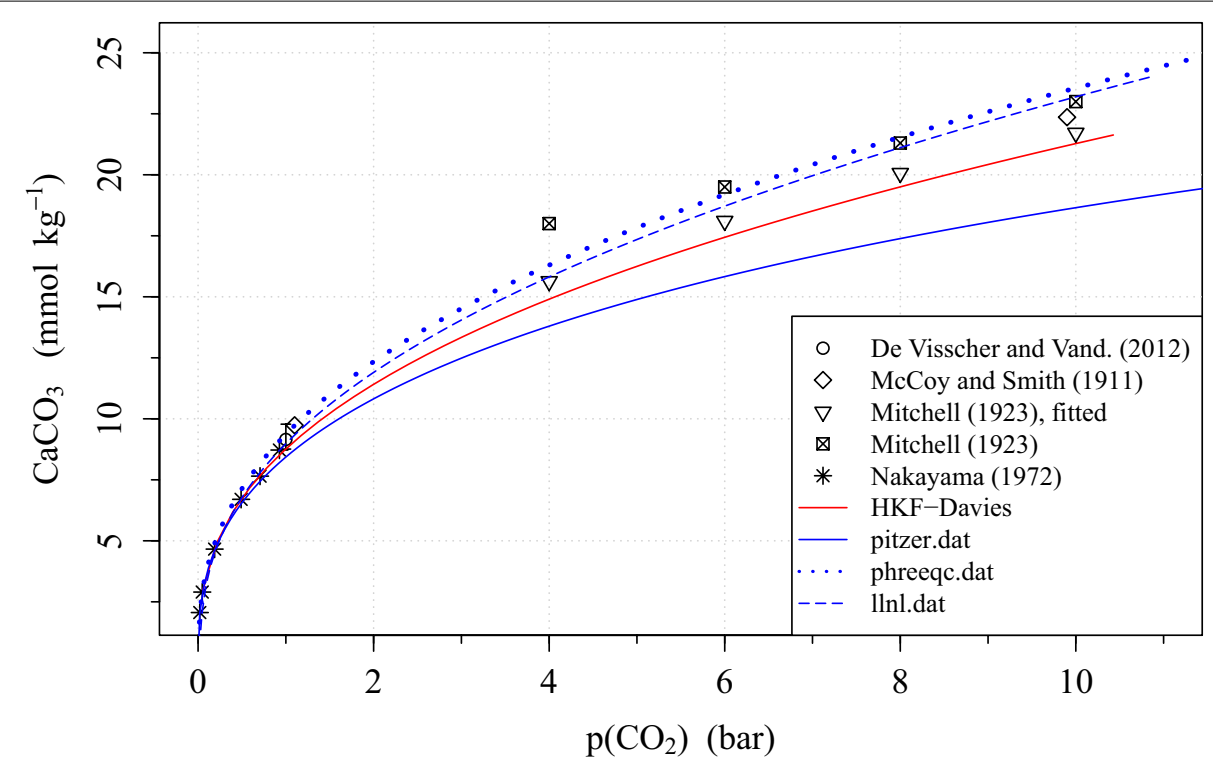

Fig. 10 Solubility of calcite at $25^{\circ} \mathrm{C}$ as a function of $\mathrm{CO}_{2}$ partial pressure. See text for additional information on sources

An enlargement for lower partial pressures is shown in Fig. 10 which covers the $\mathrm{CO}_{2}$ partial pressure regions encountered in geothermal systems without excess $\mathrm{CO}_{2}$. Data from Mitchell (1923) are presented as original data and as the regression model 2 from Visscher and Vanderdeelen (2012). The reasons for this are deviations in experimental data exceeding $10 \%$ from the solubility model presented by the latter. For a detailed explanation, see the section "Calcite" in the methods. Data for $1 \mathrm{~atm}$ in Fig. 10 comprise 20 data points from various authors compiled in Visscher and Vanderdeelen (2012). Variance for these data is given as error bar. From a qualitative point of view, phreeqc.dat, llnl. dat and HKF provide the best results for calcite solubility. As already shown in Fig. 9 for higher pressures, pitzer.dat falls below experimental data at partial pressures above 1 bar.

Additionally, pitzer.dat and phreeqc.dat deviate from each other, although there is no difference in calculation method for dilute solutions because both calculation methods use the extended Debye-Hückel equation and Pitzer parameters do not have an impact if solutions are dilute. The difference in solubilities calculated from those parameter files is too high to be attributed to the minor difference in $\log _{10} \mathrm{~K}$ values of the parameter files ( -8.406 in pitzer.dat and -8.48 in phreeqc.dat).

A detailed look at the speciation output of these calculations reveals the formation of a calcium bicarbonate complex $\left(\mathrm{CaHCO}_{3}{ }^{+}\right)$using phreeqc.dat. This poses the question if the thermodynamic data for calcite in combination with the speciation model in pitzer. dat or phreeqc.dat is appropriate for geothermal fluids containing high amounts of $\mathrm{CO}_{2}$ at high temperatures. In general, the tendency to form complexes is increased at higher temperatures. This implies that thermodynamic data and speciation model valid at, e.g. $25{ }^{\circ} \mathrm{C}$ do not have to be appropriate for higher temperatures and once more demonstrates that complex formation constants and solubility constant need to be established in a consistent manner and can never be regarded as independent from each other.

Salinity of the fluid strongly influences the solubility of calcite. Experimental results for varying ionic strengths at low $\mathrm{CO}_{2}$ partial pressures are shown in Fig. 11. The 


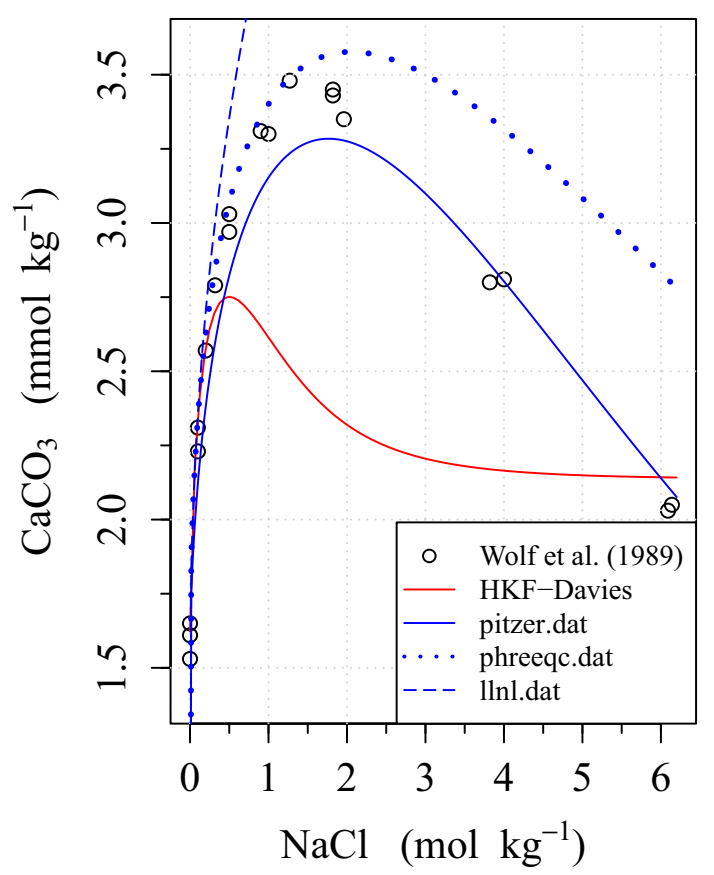

Fig. 11 Calcite solubility in $\mathrm{NaCl}$ solutions at $25^{\circ} \mathrm{C}$ and $p\left(\mathrm{CO}_{2}\right)=0.01$ bar

HKF-Davies approach is able to describe the solubility behaviour of calcite up to an ionic strength of 0.2 molal. Above 0.2 molal, the error becomes increasingly larger until the model fails at an ionic strength exceeding 0.5 molal. For ionic strengths up to 1 molal phreeqc.dat matches nicely. At higher ionic strengths, solubility is considerably too high, which is possibly due to the validity limit of the extended Debye-Hückel equation being exceeded. The best agreement for the high ionic strength data ( $>1$ molal) is achieved using pitzer.dat, but performance is hampered in the ionic strength region of 1-2 molal $\mathrm{NaCl}$ solutions, where the maximum error is up to about $0.15 \mathrm{mmol}$. llnl.dat shows high deviations at ionic strengths exceeding 0.15 molal. This can be attributed to the activity model and the formation of chloride complexes $\mathrm{CaCl}^{+}$and $\mathrm{CaCl}_{2}$ in llnl.dat.

A closer representation of geothermal systems concerning the temperature and pressure conditions is shown in Fig. 12, where experimental data were recalculated at a $\mathrm{CO}_{2}$ partial pressure of $12 \mathrm{~atm}$. The HKF-Davies approach shows good applicability up to temperatures of $160^{\circ} \mathrm{C}$. At higher temperatures, the model starts to slightly deviate from experimental data up to $0.16 \mathrm{mmol}$ at $250^{\circ} \mathrm{C}$. This can be attributed to minor deviations in calculation of the activity coefficients and of the speciation model, which is temperature and pressure corrected. Calculations with phreeqc.dat show the temperature limits of applicability for the carbonate system which is at around $180^{\circ} \mathrm{C}$. At higher temperatures, the solubility curves go through a minimum and then increase which is certainly not the behaviour of the real solubility function. Furthermore, experimental values for 1 molal $\mathrm{NaCl}$ solutions cannot be reproduced. While llnl.dat shows very good agreement at an ionic strength of 0.2 molal, it significantly falls below data in 1.0 molal $\mathrm{NaCl}$ solutions. The best result is obtained with pitzer.dat which shows an excellent agreement with all experimental values considered in this figure. 


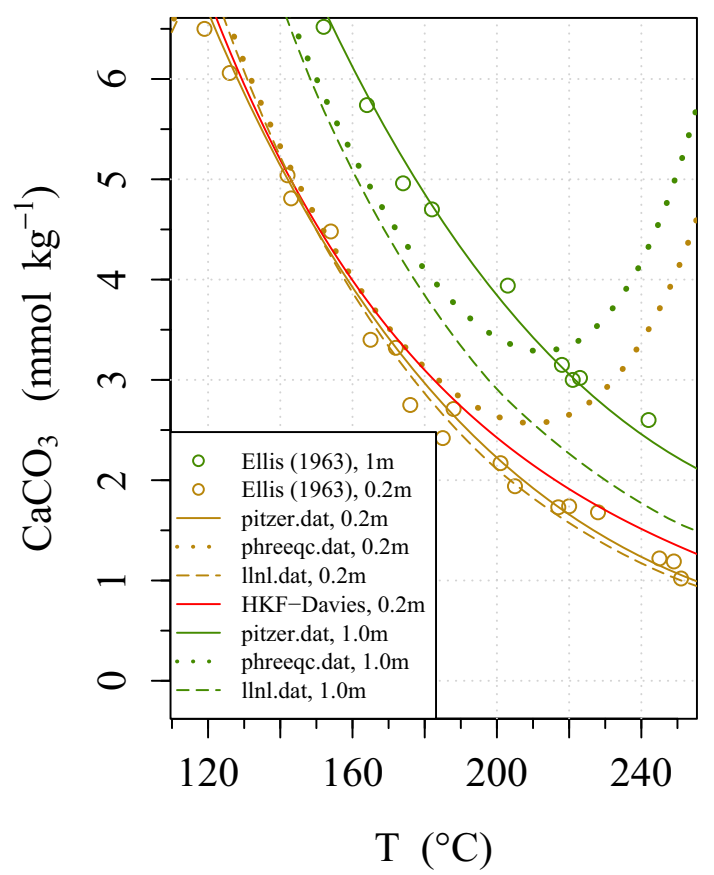

Fig. 12 Temperature-dependent solubility of calcite in $\mathrm{NaCl}$ at $p\left(\mathrm{CO}_{2}\right)=12$ atm. Molality is abbreviated with " $\mathrm{m}$ " in the legend

Shi et al. (2013) measured calcite solubility at high pressures. The experimental data were recalculated by Appelo (2015), who reported a "reasonably well" reproducibility of the solubility data in 0.1 molal $\mathrm{NaCl}$ solutions but not for the 4 molal $\mathrm{NaCl}$ data, where the model diverges considerably. The recalculations for calcite in 0.1 molal $\mathrm{NaCl}$ solutions are shown in Fig. 13; deviations from experimental data at $100{ }^{\circ} \mathrm{C}$-being the most relevant temperature among the measured-are displayed in Table 6. The HKF-Davies

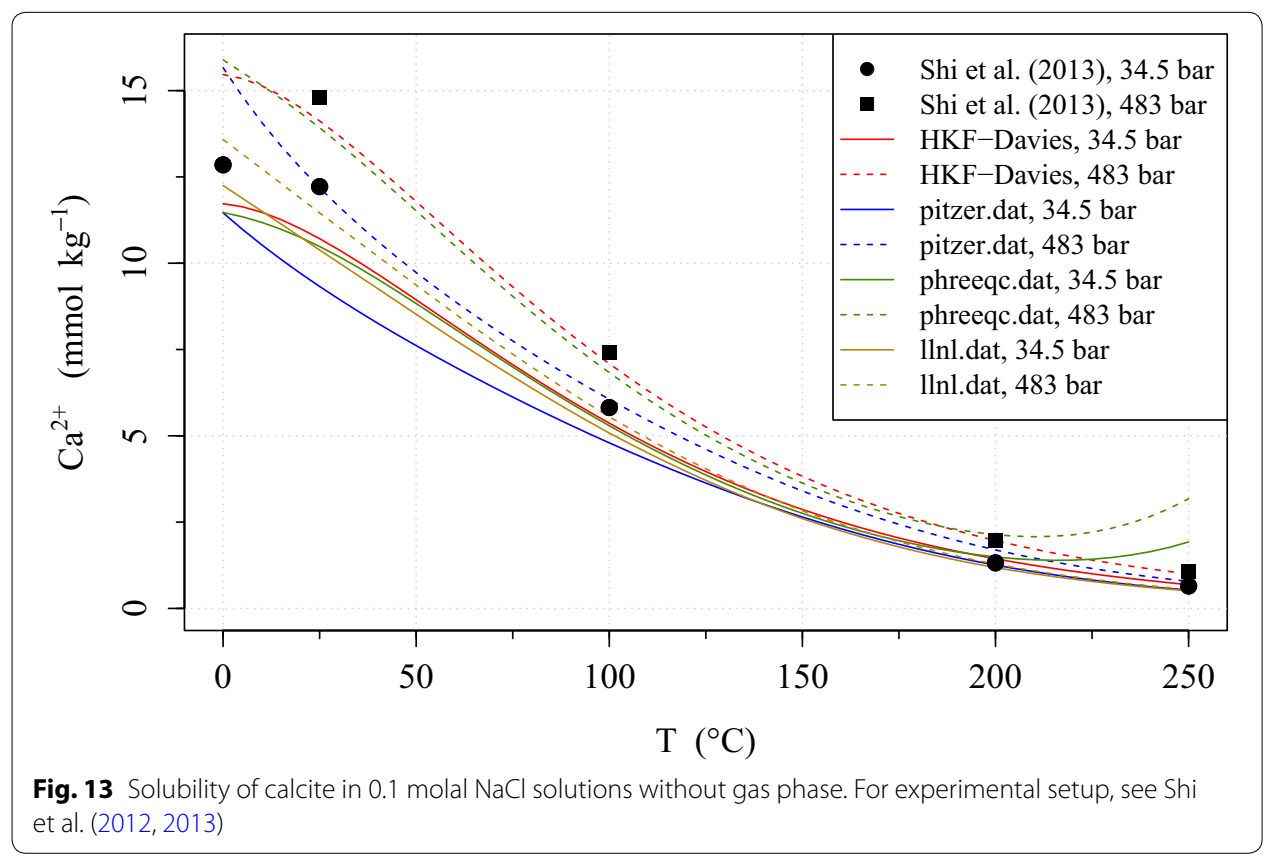


Table 6 Deviation from experimental data in Fig. 13

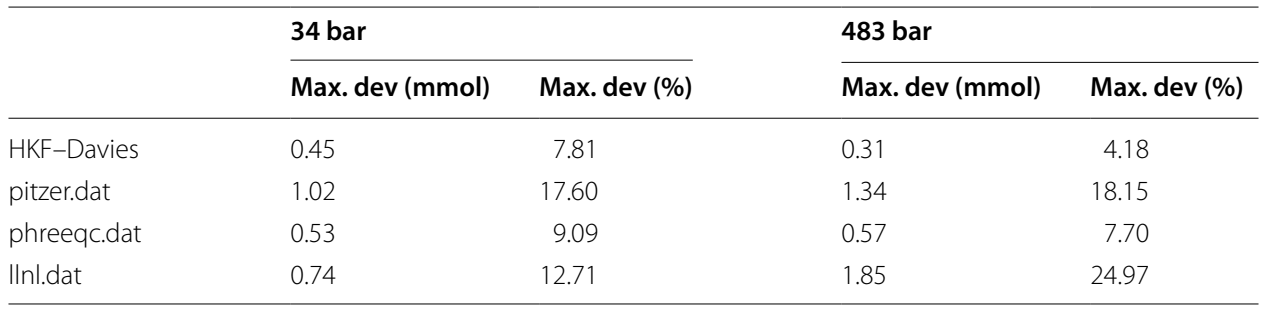

approach has the smallest divergence from experimental data with a maximum error of $7.81 \%$. Especially, the agreement for high pressure data (483 bar) is very good. Solubilities calculated with pitzer.dat are consistently too low at temperatures below $200{ }^{\circ} \mathrm{C}$ and have the highest deviation among the 34 bar calculations (17.6\%). The results form phreeqc.dat are very similar to those obtained with the HKF approach, although solubilities are a little lower. At temperatures above about $180^{\circ} \mathrm{C}$, phreeqc.dat is not applicable for the carbonate system, as the parametrisation of a temperature function leads to an increase above the limiting temperature (compare with Fig. 12). In the parameter file llnl. dat, no pressure dependence is included. The deviations between the two curves at different pressures can be related to the pressure-dependent autoprotolysis of water. While the lack of pressure dependence equations is not obvious for the 34 bar data, where llnl. dat shows a reasonable well agreement, the results for 483 bar are significantly too low with an error at $100{ }^{\circ} \mathrm{C}$ of $25 \%$.

The data from Shi et al. (2013) show that at $100{ }^{\circ} \mathrm{C}$, the difference in calcite solubility is $1.6 \mathrm{mmol} / \mathrm{kg}$ for a pressure decrease of about $450 \mathrm{bar}$. This means that there is a significant change in the thermodynamic equilibrium when producing fluids from deep geothermal reservoirs. The change in solubility due to pressure release is equal to decreasing the partial pressure of $\mathrm{CO}_{2}$ from 4 to 1 bar at $100{ }^{\circ} \mathrm{C}$ (cf. Fig. 9). Total system pressure therefore is considered as a significant boundary condition for modelling of carbonate equilibria.

\section{Siderite}

Currently, siderite is contained in databases and parameter files with different temperature corrections. The data block below shows the implementation in phreeqc.dat, where no fitted temperature function for the $\log _{10} \mathrm{~K}$ value is provided. Only a $\Delta_{r} H$ value is given in line 4 of the parameter file entry (see below), which allows a temperature correction using a two-term extrapolation (Eq. 2). The parameter file pitzer.dat does not contain siderite. The source for siderite in slop16.dat is Helgeson et al. (1978), or to be precise an erratum thereof (Helgeson 1985), where thermodynamic data for siderite were revised. The temperature function for $\log _{10} \mathrm{~K}$ in llnl.dat is very similar to those data. 


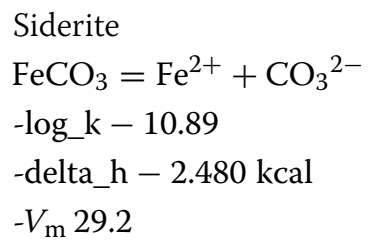

The work of Bénézeth et al. (2009) provides thorough measurement and $\log _{10} \mathrm{~K}$ evaluation for siderite in the range of $25-250{ }^{\circ} \mathrm{C}$ in 0.1 molal $\mathrm{NaCl}$ solutions. It furthermore contains a function for the temperature dependence of $\log _{10} \mathrm{~K}$, which was implemented in pitzer.dat by the authors using the "-analytic" identifier (line 5 of the following data block). This identifier contains the factors for a polynomial function and indicates PHREEQC to calculate the $\log _{10} \mathrm{~K}$ value at the temperature of interest by using Eq. (1) and the parameters given in line 5 of the following data block. In case the temperature function is defined with an analytic identifier, the $\Delta_{r} H$ values for temperature correction become obsolete.

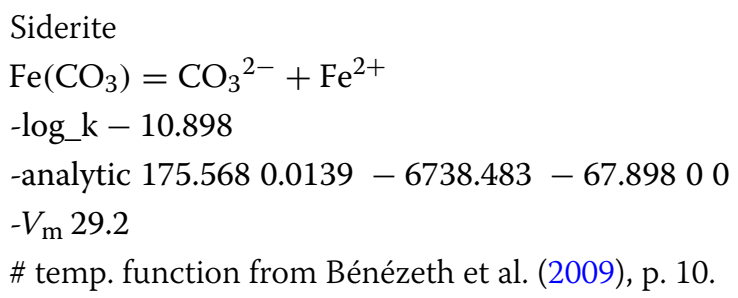

Solubility data from Bénézeth et al. (2009) were recalculated with different thermodynamic databases in PHREEQC. The slop16.dat database was not evaluated because the $\mathrm{pH}$ had to be fixed in the calculation. An iterative solution for this problem is implemented in PHREEQC; however, in the code we use for the calculations with the ChemApp programming library, this capability is not implemented and therefore the $\mathrm{pH}$ could not be fixed. This problem applies to all simulations for siderite in the present work. It is generally possible to solve this issue by modification of the code, which makes use of the subroutines in ChemApp; however, this could not be done in the frame of the present study.

The results are shown in Fig. 14. Although very thoroughly measured, there is some amount of experimental uncertainty associated with the experimental data. For $25{ }^{\circ} \mathrm{C}$ solubility does not clearly show an expected solubility increase with increasing hydrogen activity. The four data points below $-\log \left[\mathrm{H}^{+}\right]$activity of 5 were measured with the addition of 4 bar $\mathrm{CO}_{2}$ and $\mathrm{HCl}$, whereas the rest of the data points were measured with addition of $\mathrm{HCl}$ only.

As a representative of the HKF family of databases, llnl.dat was chosen, which has very similar $\log _{10} \mathrm{~K}$ for siderite compared to slop16.dat. Calculations with llnl.dat at the lower range of temperatures measured (up to $99^{\circ} \mathrm{C}$ ) show solubilities consistently too high compared to experimental data. At higher temperatures, the model performs comparatively well. While providing reasonable agreement for the solubility at $25^{\circ} \mathrm{C}$, phreeqc. dat increasingly deviates at higher temperatures, leading to large errors at temperatures above $100{ }^{\circ} \mathrm{C}$. This may be related to the fact that phreeqc.dat has a temperature 


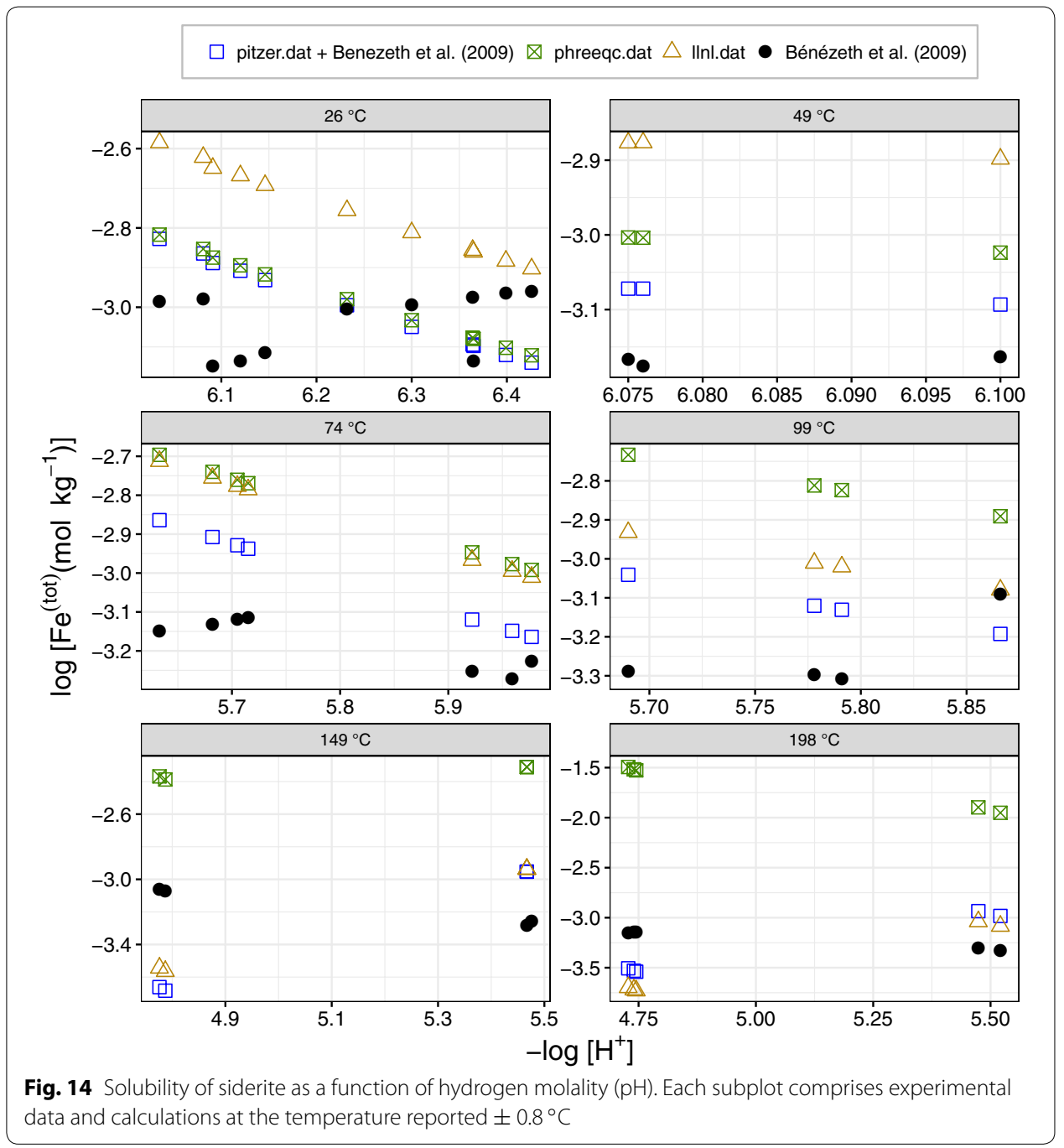

correction with $\Delta_{r} H$ (two-term extrapolation) only. The parameter file pitzer.dat was extended in this study with siderite (which is by default not included in the parameter file) using the temperature function from Bénézeth et al. (2009). It provides the best representation of the experimental data, which is expected as it contains the temperature function regressed on the experimental values shown in the diagram. Note that in this calculation, phreeqc.dat and pitzer.dat yield identical results if the same temperature function for $\log _{10} \mathrm{~K}$ is implemented.

For siderite solubility in $\mathrm{NaCl}$ solutions of different ionic strength, experimental data were recalculated. The accuracy of the measurements should be regarded with care, as there is almost no difference in siderite solubility between, e.g. 1.4 and 2.5 molal $\mathrm{NaCl}$ solutions, which argues for a significant experimental uncertainty. Measuring an accurate $\mathrm{pH}$ value in brines is challenging and can be a significant source of error (Marcus 1989). Hagemann et al. (2014) showed that the experimental error from potentiometric titration can be up to $0.8 \mathrm{pH}$ units in 5.5 molal $\mathrm{NaCl}$ solutions and up to $0.2 \mathrm{pH}$ units in 2 molal $\mathrm{NaCl}$ solutions. 
None of the models applied is able to provide a good agreement with experimental data in Fig. 15. A major difference between the models can be seen when looking at the shape of the curves: llnl.dat and phreeqc.dat show an increase in solubility at neutral to alkaline pHs, while solubility in pitzer.dat continuously decreases. This can be attributed to the fact that in contrast to phreeqc.dat and llnl.dat, pitzer.dat contains no ferrous complexes. These complexes increasingly form at higher $\mathrm{pH}$ values and thereby increase the solubility of siderite. As a consequence, the lack of ferrous complexes only allows for calculations with pitzer.dat at $\mathrm{pH}$ values below 7 .

Solubilities are consistently too high in calculations with llnl.dat. This is due to two reasons: Firstly, the more positive $\log _{10} \mathrm{~K}$ value of -10.57 than in phreeqc.dat $(-10.89)$, which translates into more siderite being dissolved and secondly, the higher concentration of complexes appearing in calculated results, which increase solubility of siderite. Even the calculation at an ionic strength of 0.1 molal with llnl.dat is significantly too high, which argues for an inadequate speciation model in combination with the $\log _{10} \mathrm{~K}$ value of the parameter file. The calculations from phreeqc.dat overestimate the solubility in 0.1 molal $\mathrm{NaCl}$ solution. The fit with data acquired in 2 molal $\mathrm{NaCl}$ solutions is good, but given the performance in solutions with lower ionic strength, it might well be possible that this coincidence is fortuitous.

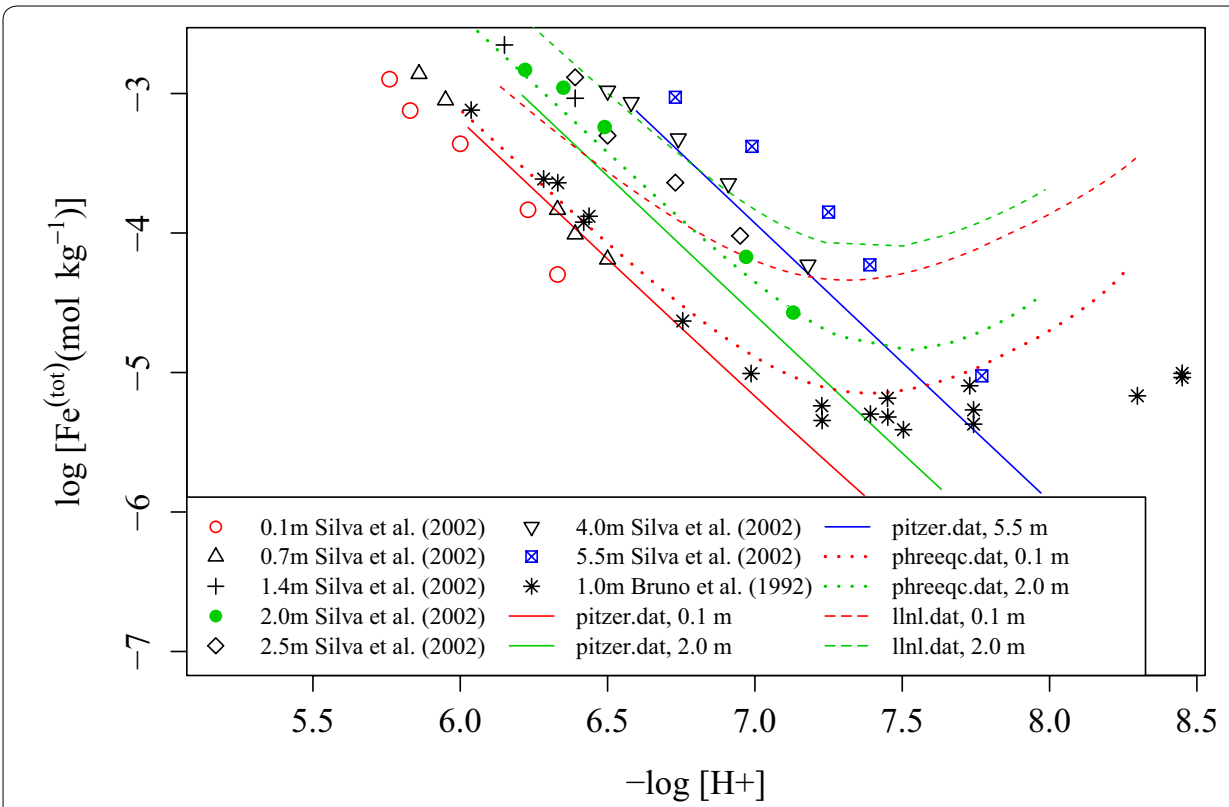

Fig. 15 Solubility of siderite at $25^{\circ} \mathrm{C}$ and $p\left(\mathrm{CO}_{2}\right)=0.05 \mathrm{~atm}$ as a function of ionic strength. Data from Bruno et al. (1992) were measured in 1 molal sodium perchlorate $\left(\mathrm{NaClO}_{4}\right)$. Molality is abbreviated with " $\mathrm{m}$ " in the legend. Note that siderite was implemented in pitzer.dat using a $\log _{10} \mathrm{~K}$ of -10.898 at $25^{\circ} \mathrm{C}$ 
Currently, perchlorate $\left(\mathrm{ClO}_{4}{ }^{-}\right)$is not implemented in either of the databases used for the calculation in Fig. 15. In solubility studies, perchlorate solutions are frequently used to inspect the impact of ionic strength on the conditional solubility constant because perchlorate in contrast to chloride does not form complex species with metal cations. Furthermore, due to its different ratio of charge over ionic radius, its impact on water molecules can be expected to differ from that of chloride. Solubilities of the same mineral in $\mathrm{NaCl}^{-}$or $\mathrm{NaClO}_{4}$ solutions can therefore not be directly compared and are likely to be different. It is not surprising that Fanghänel et al. (1996) showed that Pitzer parameters for chloride and perchlorate differ, so it is not possible to accurately recalculate solubility in $\mathrm{NaClO}_{4}$ solutions without implementing $\mathrm{ClO}_{4}{ }^{-}$in the aforementioned databases. Consequently, we chose not to recalculate the data from Bruno et al. (1992) and display them only in order to highlight the complex behaviour, which the solubility curve undergoes during transition from acidic to alkaline solutions.

It should be mentioned that we were not able to recalculate all experimental data. Appelo (2015) already mentioned that they did not succeed to reproduce the solubility experiments for calcite of Shi et al. (2012) in 4 molal $\mathrm{NaCl}$ solutions and neither did we. Furthermore, the data from (Yan et al. 2015) for siderite, originating from the same working group could not be reproduced using PHREEQC/pitzer.dat.

\section{Dolomite}

Currently, dolomite is implemented in phreeqc.dat and pitzer.dat without a temperature function but using $\Delta_{r} H$ for temperature correction of the equilibrium constant according to Eq. (2). The value for $\Delta_{r} H$ implemented in this database is $-9.436 \mathrm{kcal}(-39.48$ kJ). No data source is given. Using enthalpy of formation from Bénézeth et al. (2018) for dolomite and from Sverjensky et al. (1997) for carbonate, calcium, and magnesium results in a $\Delta_{r} H$ value of $-2286.69 \mathrm{~kJ}$. A comparison with experimental data (Fig. 16) reveals a very good agreement of the PHREEQC parameter files with the, according to Sherman and Barak (2000), widely used $\log _{10} \mathrm{~K}$ value at $25{ }^{\circ} \mathrm{C}$ from Hemingway and Robie (1994) and Robie and Hemingway (1995). However, at temperatures exceeding $50{ }^{\circ} \mathrm{C}$, PHREEQC parameter files start to significantly deviate from measured solubility data. The reason for this might be the outdated value for $\Delta_{r} H$ implemented in those parameter files. The slop16 temperature function evaluated with CHNOSZ significantly deviates from experimental data at temperatures below $125{ }^{\circ} \mathrm{C}$ (Fig. 16). The reason for this deviation was already discussed in Bénézeth et al. (2018) and we agree with their explanation that differences are due to thermodynamic data "which was derived from extrapolating high temperature phase relations to ambient temperatures using estimated entropies and heat capacity power functions". The slop16.dat temperature function is also used in EQ3/6 (e.g. data.ypf) and GWB (e.g. thermo.tdat, thermo.com.V8.R6+. tdat). The temperature function from llnl.dat very much resembles slop16.dat, but shows some minor deviations. To the author's knowledge, the temperature function was taken from slop (with SUPCRT92), converted into a temperature grid and then refitted with a polynomial equation to transfer it into a PHREEQC parameter file. This refitting procedure leads to the small offset at some temperatures.

The current implementation of the temperature functions in all thermodynamic data files represent the knowledge prior to the publication of new data by Bénézeth et al. 


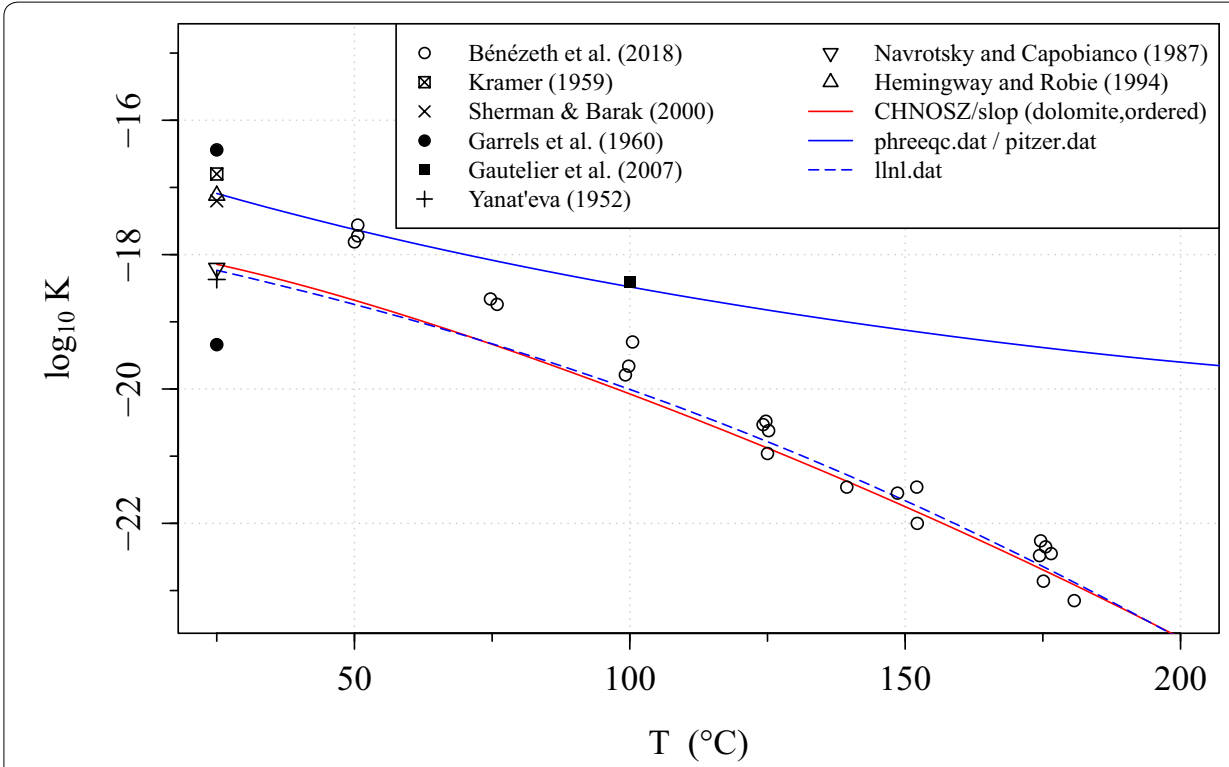

Fig. 16 Temperature function of the $\log _{10} \mathrm{~K}$ of dolomite compared with experimental data. Value of Navrotsky and Capobianco (1987) was calculated with data from Robie and Hemingway (1995)

(2018), where no direct solubility measurements at temperatures above $25{ }^{\circ} \mathrm{C}$ existed. The only exception was one datum, determined at $80{ }^{\circ} \mathrm{C}$ from Gautelier et al. (2007). The temperature functions for dolomite illustrate that the usage of extrapolations on few experimental data and beyond the temperature limits of experiments can lead to faulty predictions if applied to real systems. This is exacerbated by the fact that the validity ranges for temperatures is usually not documented in the parameter files.

\section{Conclusion}

Selected thermodynamic data files (phreeqc.dat, pitzer.dat, llnl.dat, and slop16.dat) were tested against experimental data at geothermal temperature and pressure conditions. The benchmarking revealed outdated equilibrium constants for celestite in the slop16. dat database which produce erroneous results. It was furthermore shown in the case of barite that the speciation model can have a profound impact on the modelling results and that speciation models and solubility constants of minerals cannot be regarded independently from each other. It furthermore illustrated that apparently sound and well-established thermodynamic data (e.g. $\log _{10} \beta$ for $\mathrm{BaCl}^{+}$) are in fact ill-defined by insufficient experimental data.

The temperature dependence implemented in all files for siderite and dolomite is inadequate for most calculations. A new temperature function was included for siderite in pitzer.dat using thermodynamic data from (Bénézeth et al. 2009), which allows modelling siderite solubility up to temperatures of $250^{\circ} \mathrm{C}$ in acidic solutions. These thermodynamic data are not yet available in the files distributed with PHREEQC. The parameter files pitzer.dat and phreeqc.dat can be used from scratch for high pressure (up to approx. 500 bar), high temperature modelling of barite, celestite, and calcite. However, phreeqc. dat is limited to about $190{ }^{\circ} \mathrm{C}$ due to the formation of $\mathrm{CaHCO}_{3}{ }^{+}$creating an unrealistic solubility minimum at those temperatures. For calcite solubility, slop16.dat can be 
applied at high temperatures and pressures up to an ionic strength of about $0.4 \mathrm{~mol} / \mathrm{kg}$ and yields the best results for high pressure calculations of calcite.

Some parameter file entries for EQ 3/6 and Geochemist's Workbench were checked for the mineral phases validated in the present work. The check revealed that outdated equilibrium constants for celestite were transferred to some of those files if they had not undergone revision, as they are derived from previous versions of slop16.dat.

Especially for highly saline fluids, there is currently no parameter file or database which can be applied from scratch for all scale-forming minerals in low-enthalpy geothermal fields. Regarding some scale-forming sulphide minerals and heavy metal scalings, no thermodynamic data at all are implemented for high salinity. The results reveal a fundamental problem with thermodynamic data files where the range of validity for temperature functions is not documented. Since the temperature and pressure dependency of the equilibrium constants is often based on empirical relations regressed to experimental data, these entries should not be used outside the range of underlying experimental data. This paper should be regarded as a documented benchmark to assess the validity of widely used thermodynamic data files and the range of conditions for which these functions can be applied safely.

The authors would like to stress that such test calculations are actually mandatory for everyone applying geochemical calculations to real systems. If this were common practice, a significant lack of experimental data would become apparent and eventually lead to efforts to close those data gaps rather than performing modelling studies without an appropriate knowledge of the real behaviour of complex systems. Obtaining and implementing additional experimentally determined thermodynamic data into databases and parameter files can greatly enhance the significance and accuracy of complex hydrogeochemical models in the future if consistency in the database or parameter file is maintained.

Authors' contributions

TH wrote the manuscript, researched solubility data, and did the thermodynamic equilibrium modelling. TB provided scientific supervision of the thesis, which led to this paper, ideas for data evaluation and representation, debugging of code, and critical appraisal of hypotheses and results. HCM initiated this study, provided solubility data and code for ChemApp, and critically appraised hypotheses and results. All authors read and approved the final manuscript.

\section{Author details}

${ }^{1}$ Erdwerk GmbH, Bonner Platz 1, 80803 München, Germany. ${ }^{2}$ Institute of Hydrochemistry, Technical University of Munich, Marchioninistr. 17, 81377 München, Germany. ${ }^{3}$ GRS gGmbH, Theodor-Heuss-Straße 4, 38122 Braunschweig, Germany.

\section{Acknowledgements}

Tatjana Jantzen and Gunnar Eriksson from GTT Technologies are thanked for helping with translation of slop16.dat into a ChemApp readable format. Christophe Monnin from GET is thanked for the solubility data of barite. We also thank two anonymous reviewers for their insightful comments, which greatly improved the work.

\section{Competing interests}

The authors declare that they have no competing interests.

\section{Publisher's Note}

Springer Nature remains neutral with regard to jurisdictional claims in published maps and institutional affiliations.

Received: 15 March 2018 Accepted: 27 September 2018

Published online: 12 October 2018

\section{References}

Appelo C. Principles, caveats and improvements in databases for calculating hydrogeochemical reactions in saline waters from 0 to $200^{\circ} \mathrm{C}$ and 1 to 1000 atm. Appl Geochem. 2015;55:62-71. https://doi.org/10.1016/j.apgeo chem.2014.11.007. 
Appelo C, Parkhurst DL, Post V. Equations for calculating hydrogeochemical reactions of minerals and gases such as $\mathrm{CO}_{2}$ at high pressures and temperatures. Geochimica et Cosmochimica Acta. 2014;125:49-67. https://doi.org/10.1016/j. gca.2013.10.003.

Baumann T, Bartels J, Lafogler M, Wenderoth F. Assessment of heat mining and hydrogeochemical reactions with data from a former geothermal injection well in the Malm Aquifer, Bavarian Molasse Basin, Germany. Geothermics. 2017;66:50-60. https://doi.org/10.1016/j.geothermics.2016.11.008.

Bénézeth P, Dandurand $\mathrm{JL}$, Harrichoury JC. Solubility product of siderite $\left(\mathrm{FeCO}_{3}\right)$ as a function of temperature $\left(25-250^{\circ} \mathrm{C}\right)$. Chem Geol. 2009;265(1-2):3-12. https://doi.org/10.1016/j.chemgeo.2009.03.015.

Bénézeth P, Berninger UN, Bovet N, Schott J, Oelkers EH. Experimental determination of the solubility product of dolomite at 50-253 ${ }^{\circ} \mathrm{C}$. Geochimica et Cosmochimica Acta. 2018;224:262-75. https://doi.org/10.1016/j.gca.2018.01.016.

Bethke CM. Geochemical and biogeochemical reaction modeling. Cambridge: Cambridge University Press; 2007. https:// doi.org/10.1017/CBO9780511619670.

Blount CW. Barite solubilities and thermodynamic quantities up to $300^{\circ} \mathrm{C}$ and 1400 bar. Am Mineral. 1977;62(9-10):942-57.

Bruno J, Wersin P, Stumm W. On the influence of carbonate in mineral dissolution: II. The solubility of $\mathrm{FeCO}_{3}(\mathrm{~s})$ at $25^{\circ} \mathrm{C}$ and $1 \mathrm{~atm}$ total pressure. Geochimica et Cosmochimica Acta. 1992;56(3):1149-55. https://doi.org/10.1016/00167037(92)90052-K.

Coto B, Martos C, Peña JL, Rodríguez R, Pastor G. Effects in the solubility of $\mathrm{CaCO}_{3}$ : experimental study and model description. Fluid Phase Equilibria. 2012;324:1-7. https://doi.org/10.1016/j.fluid.2012.03.020.

Culberson $\mathrm{CH}$, Latham $\mathrm{G}$, Bates RG. Solubilities and activity coefficients of calcium and strontium sulfates in synthetic sea water at 0.5 and $25^{\circ} \mathrm{C}$. J Phys Chem. 1978;82(25):2693-9. https://doi.org/10.1021/j100514a012.

Davies CW. The extent of dissociation of salts in water. Part VIII. An equation for the mean ionic activity coefficient of an electrolyte in water, and a revision of the dissociation constants of some sulphates. J Chem Soc. 1938. https://doi. org/10.1039/jr9380002093.

Davis JW, Collins AG. Solubility of barium and strontium sulfates in strong electrolyte solutions. Environ Sci Technol. 1971:5(10):1039-43. https://doi.org/10.1021/es60057a007.

de Lucia M, Bauer S, Beyer C, Kühn M, Nowak T, Pudlo D, Reitenbach V, Stadler S. Modelling $\mathrm{CO}_{2}$-induced fluid-rock interactions in the Altensalzwedel gas reservoir. Part I: from experimental data to a reference geochemical model. Environ Earth Sci. 2012;67(2):563-72. https://doi.org/10.1007/s12665-012-1725-9.

Debye P, Hückel E. Zur Theorie der Elektrolyte. I. Gefrierpunktserniedrigung und verwandte erscheinungen. Physikalische Z. 1923:46(9):185-206.

Dick JM. Calculation of the relative metastabilities of proteins using the CHNOSZ software package. Geochem Trans. 2008:9:10.

Doubra P, Kamran-Pirzaman A, Mohammadi AH, Hassanalizadeh R. Thermodynamic modelling of scale (calcite, barite, anhydrite and gypsum) deposition from brine. J Mol Liquids. 2017;230:96-103. https://doi.org/10.1016/..molli q.2016.11.135.

Ellis AJ. The solubility of calcite in sodium chloride solutions at high temperatures. Am J Sci. 1963;261(3):259-67. https:// doi.org/10.2475/ajs.261.3.259.

Eriksson G, Petersen S. ChemApp - the thermochimistry library for your software: programmer's manual edition 3.14 2013. http://www.gtt-technologies.de/chemapp/chemapp-programmers-manual.

Fanghänel T, Neck V, Kim Jl. The ion product of $\mathrm{H}_{2} \mathrm{O}$, dissociation constants of $\mathrm{H}_{2} \mathrm{CO}_{3}$ and pitzer parameters in the system $\mathrm{Na}^{+} / \mathrm{H}^{+} / \mathrm{OH}^{-} / \mathrm{HCO}_{3}{ }^{-} / \mathrm{CO}_{3}{ }^{2-} / \mathrm{ClO}_{4}{ }^{-} / \mathrm{H}_{2} \mathrm{O}$ at $25^{\circ} \mathrm{C}$. J Solut Chem. 1996;25(4):327-43. https://doi.org/10.1007/ BF00972890.

Fritz B, Jacquot E, Jacquemont B, Baldeyrou-Bailly A, Rosener M, Vidal O. Geochemical modelling of fluid-rock interactions in the context of the Soultz-sous-Forêts geothermal system. Comptes Rendus Geosci. 2010;342(7-8):653-67. https://doi.org/10.1016/j.crte.2010.02.005.

Garrels RM, Thompson ME, Siever R. Stability of some carbonates at $25^{\circ} \mathrm{C}$ and one atmosphere total pressure. Am J Sci. 1960;258(6):402-18.

Gautelier M, Schott J, Oelkers EH. An experimental study of dolomite dissolution rates at $80^{\circ} \mathrm{C}$ as a function of chemical affinity and solution composition. Chem Geol. 2007;242(3-4):509-17. https://doi.org/10.1016/j.chemg eo.2007.05.008

Gholizadeh Doonechaly N, Abdel Azim R, Rahman SS. Evaluation of recoverable energy potential from enhanced geothermal systems: a sensitivity analysis in a poro-thermo-elastic framework. Geofluids. 2016;16(3):384-95. https://doi. org/10.1111/gfl.12156.

Giffaut E, Grivé M, Blanc P, Vieillard P, Colàs E, Gailhanou H, Gaboreau S, Marty N, Madé B, Duro L. Andra thermodynamic database for performance assessment: thermoChimie. Appl Geochem. 2014;49:225-36. https://doi.org/10.1016/j. apgeochem.2014.05.007.

Golubev SV, Bénézeth P, Schott J, Dandurand JL, Castillo A. Siderite dissolution kinetics in acidic aqueous solutions from 25 to $100^{\circ} \mathrm{C}$ and 0 to $50 \mathrm{~atm} \mathrm{pCO}$. Chem Geol. 2009;265(1-2):13-9. https://doi.org/10.1016/j.chemgeo.2008.12.031.

Haase C, Dethlefsen F, Ebert M, Dahmke A. Uncertainty in geochemical modelling of $\mathrm{CO}_{2}$ and calcite dissolution in $\mathrm{NaCl}$ solutions due to different modelling codes and thermodynamic databases. Appl Geochem. 2013;33:306-17. https:// doi.org/10.1016/j.apgeochem.2013.03.001.

Hagemann S, Bischofer B, Scharge T, Schönwiese D. Entwicklung von methoden und modellen zur bestimmung des redoxpotentials salinarer Lösungen. Braunschweig: GRS; 2014

Helgeson HC. Errata II; Thermodynamics of minerals, reactions, and aqueous solutions at high pressures and temperatures. Am J Sci. 1985;285(9):845-55. https://doi.org/10.2475/ajs.285.9.845.

Helgeson HC, Delany JM, Nesbitt HW, Bird DK. Summary and critique of the thermodynamic properties of rock-forming minerals. Am J Sci. 1978:278(A):1-229.

Helgeson HC, Kirkham DH, Flowers GC. Theoretical prediction of the thermodynamic behavior of aqueous electrolytes by high pressures and temperatures; IV, calculation of activity coefficients, osmotic coefficients, and apparent molal 
and standard and relative partial molal properties to $600^{\circ} \mathrm{C}$ and $5 \mathrm{~kb}$. Am J Sci. 1981;281(10):1249-516. https://doi. org/10.2475/ajs.281.10.1249.

Hemingway BS, Robie RA. Enthalpy and Gibbs energy of formation of dolomite, $\mathrm{CaMg}\left(\mathrm{CO}_{3}\right)_{2}$, at $298.15 \mathrm{~K}$ from HCl solution calorimetry. New York: ACM; 1994. p. 94-575.

Howell RD, Raju K, Atkinson G. Thermodynamics of scale mineral solubilities. 4. Experimental measurements of strontium sulfate(s) in water and aqueous sodium chloride from 25 to $250^{\circ} \mathrm{C}$ and from 1 to 500 bar. J Chem Eng Data. 1992;37(4):464-9. https://doi.org/10.1021/je00008a020.

Johnson JW, Oelkers EH, Helgeson HC. SUPCRT92: a software package for calculating the standard molal thermodynamic properties of minerals, gases, aqueous species, and reactions from 1 to $5000 \mathrm{bar}$ and 0 to $1000^{\circ} \mathrm{C}$. Comput Geosci. 1992;18(7):899-947. https://doi.org/10.1016/0098-3004(92)90029-Q.

Kramer J. Correction of some earlier data on calcite and dolomite in sea water. J Sediment Petrol. 1959;29(3):465-7.

Kulik DA, Wagner T, Dmytrieva SV, Kosakowski G, Hingerl FF, Chudnenko KV, Berner UR. GEM-Selektor geochemical modeling package: revised algorithm and GEMS3K numerical kernel for coupled simulation codes. Comput Geosci. 2013;17(1):1-24.

Lucchesi PJ, Whitney ED. Solubility of strontium sulphate in water and aqueous solutions of hydrogen chloride, sodium chloride, sulphuric acid and sodium sulphate by the radiotracer method. J Appl Chem. 1962;12(6):2779. https://doi.org/10.1002/jctb.5010120607.

Magnenet V, Fond C, Genter A, Schmittbuhl J. Two-dimensional THM modelling of the large scale natural hydrothermal circulation at Soultz-sous-Forêts. Geotherm Energy. 2014;2(1):533. https://doi.org/10.1186/s4051 7-014-0017-X.

Majer V, Stulik K. A study of the stability of alkaline-earth metal complexes with fluoride and chloride ions at various temperatures by potentiometry with ion-selective electrodes. Talanta. 1982;29(2):145-8. https://doi. org/10.1016/0039-9140(82)80039-8.

Major M, Poulsen SE, Balling N. A numerical investigation of combined heat storage and extraction in deep geothermal reservoirs. Geotherm Energy. 2018;6(1):540. https://doi.org/10.1186/s40517-018-0089-0.

Marcus Y. Determination of pH in highly saline waters. Pure Appl Chem. 1989;61 (6):1133-8.

McCoy HN, Smith HJ. Equilibrium between alkali-earth carbonates, carbon dioxide and water. J Am Chem Soc. 1911;33(4):468-73. https://doi.org/10.1021/ja02217a003.

Melcher AC. The solubility of silver chloride, barium sulphate and calcium sulphate at high temperatures. J Am Chem Soc. 1910;32(1):50-66. https://doi.org/10.1021/ja01919a003.

Miller JP. A portion of the system calcium carbonate-carbon dioxide-water, with geological implications. Am J Sci. 1952;250(3):161-203. https://doi.org/10.2475/ajs.250.3.161.

Miron GD, Kulik DA, Dmytrieva SV, Wagner T. GEMSFITS: code package for optimization of geochemical model parameters and inverse modeling. Appl Geochem. 2015;55:28-45. https://doi.org/10.1016/j.apgeochem.2014.10.013.

Miron GD, Wagner T, Kulik DA, Heinrich CA. Internally consistent thermodynamic data for aqueous species in the system Na-K-Al-Si-O-H-Cl. Geochimica et Cosmochimica Acta. 2016;187:41-78. https://doi.org/10.1016/j. gca.2016.04.026.

Miron GD, Wagner T, Kulik DA, Lothenbach B. An internally consistent thermodynamic dataset for aqueous species in the system Ca-Mg-Na-K-Al-Si-O-H-C-Cl to $800^{\circ} \mathrm{C}$ and $5 \mathrm{kbar}$. Am J Sci. 2017;317(9):754-805.

Mitchell AE. Studies on the dolomite system. Part II. J Chem Soc Trans. 1923;123:1887-904. https://doi.org/10.1039/ CT9232301887.

Monnin C, Galinier C. The solubility of celestite and barite in electrolyte solutions and natural waters at $25^{\circ} \mathrm{C}$ : a thermodynamic study. Chem Geol. 1988;71(4):283-96. https://doi.org/10.1016/0009-2541(88)90055-1.

Moog HC, Bok F, Marquardt CM, Brendler V. Disposal of nuclear waste in host rock formations featuring high-saline solutions-implementation of a thermodynamic reference database (THEREDA). Appl Geochem. 2015;55:72-84. https://doi.org/10.1016/j.apgeochem.2014.12.016.

Müller G. Die Lösslichkeit von Coelestin ( $\mathrm{SrSO}_{4}$ ) in wässerigen $\mathrm{NaCl}$ - und KCl-Lösungen. Neues Jahrb Mineral Monatsh. 1960;1960:237-9.

Nakayama FS. Calcium ativity, complex and ion-pair in saturated $\mathrm{CaCO}_{3}$ solutions. Soil Sci. 1968;106(6):429-34.

Navrotsky A, Capobianco C. Enthalpies of formation of dolomite and of magnesian calcites. Am Mineral. 1987;72(7-8):782-7.

Neveu M, Desch SJ, Castillo-Rogez JC. Aqueous geochemistry in icy world interiors: equilibrium fluid, rock, and gas compositions, and fate of antifreezes and radionuclides. Geochimica et Cosmochimica Acta. 2017;212:324-71. https://doi.org/10.1016/j.gca.2017.06.023.

Nitschke F, Held S, Himmelsbach T, Kohl T. THC simulation of halite scaling in deep geothermal single well production. Geothermics. 2017;65:234-43. https://doi.org/10.1016/j.geothermics.2016.09.009.

Parkhurst DL. Release notes to PhreeqC. 2017. ftp://brrftp.cr.usgs.gov/pub/charlton/phreegc/RELEASE.12704.TXT.

Parkhurst DL, Appelo C. Description of input and examples for PHREEQC version 3: a computer program for speciation, batch-reaction, one-dimensional transport, and inverse geochemical calculations. Reston: Geological Survey; 2013

Petersen S, Hack K. The thermochemistry library ChemApp and its applications. Int J Mater Res. 2007;98(10):935-45.

Pitzer KS. Thermodynamics of electrolytes. I. Theoretical basis and general equations. J Phys Chem. 1973;77(2):268-77. https://doi.org/10.1021/j100621a026.

R core team. R: a language and environment for statistical computing. 2017. https://www.R-project.org.

Reardon EJ, Armstrong DK. Celestite $\left(\mathrm{SrSO}_{4}(\mathrm{~s})\right)$ solubility in water, seawater and $\mathrm{NaCl}$ solution. Geochimica et Cosmochimica Acta. 1987:51(1):63-72. https://doi.org/10.1016/0016-7037(87)90007-X.

Reed MJ. Thermodynamic calculations of calcium carbonate scaling in geothermal wells, dixie valley geothermal field, USA. Geothermics. 1989;18(1-2):269-77. https://doi.org/10.1016/0375-6505(89)90036-9.

Regenspurg S, Feldbusch E, Byrne J, Deon F, Driba DL, Henninges J, Kappler A, Naumann R, Reinsch T, Schubert C. Mineral precipitation during production of geothermal fluid from a Permian Rotliegend reservoir. Geothermics. 2015;54:122-35. https://doi.org/10.1016/j.geothermics.2015.01.003. 
Robie RA, Hemingway BS. Thermodynamic properties of minerals and related substances at $298.15 \mathrm{~K}$ and $1 \mathrm{bar}\left(10^{5}\right.$ pascals) pressure and at higher temperatures. Washington: US Government Printing Office; 1995.

Safari H, Shokrollahi A, Jamialahmadi M, Ghazanfari MH, Bahadori A, Zendehboudi S. Prediction of the aqueous solubility of $\mathrm{BaSO}_{4}$ using pitzer ion interaction model and LSSVM algorithm. Fluid Phase Equilibria. 2014a;374:48-62. https://doi.org/10.1016/j.fluid.2014.04.010.

Safari H, Shokrollahi A, Moslemizadeh A, Jamialahmadi M, Ghazanfari MH. Predicting the solubility of $\mathrm{SrSO}_{4}$ in $\mathrm{Na}-\mathrm{Ca}-$ $\mathrm{Mg}-\mathrm{Sr}-\mathrm{Cl}-\mathrm{SO}_{4}-\mathrm{H}_{2} \mathrm{O}$ system at elevated temperatures and pressures. Fluid Phase Equilibria. 2014b;374:86-101. https://doi.org/10.1016/j.fluid.2014.04.023.

Segnit ER, Holland HD, Biscardi CJ. The solubility of calcite in aqueous solutions-l: the solubility of calcite in water between $75^{\circ}$ and $200^{\circ}$ at $\mathrm{CO}_{2}$ pressures up to $60 \mathrm{~atm}$. Geochimica et Cosmochimica Acta. 1962;26(12):1301-31. https://doi.org/10.1016/0016-7037(62)90057-1.

Sherman LA, Barak P. Solubility and dissolution kinetics of dolomite in $\mathrm{Ca}-\mathrm{Mg}-\mathrm{HCO}_{3} / \mathrm{CO}_{3}$ solutions at $25^{\circ} \mathrm{C}$ and 0.1 MPa carbon dioxide. Soil Sci Soc Am J. 2000;64(6):1959. https://doi.org/10.2136/sssaj2000.6461959x.

Shi W, Kan AT, Fan C, Tomson MB. Solubility of barite up to $250^{\circ} \mathrm{C}$ and 1500 bar in up to $6 \mathrm{~m} \mathrm{NaCl}$ solution. Ind Eng Chem Res. 2012:51(7):3119-28. https://doi.org/10.1021/ie2020558.

Shi W, Kan AT, Zhang N, Tomson M. Dissolution of calcite at up to $250^{\circ} \mathrm{C}$ and 1450 bar and the presence of mixed salts. Ind Eng Chem Res. 2013;52(6):2439-48. https://doi.org/10.1021/ie302190e.

Silva C, Liu X, Millero FJ. Solubility of siderite $\left(\mathrm{FeCO}_{3}\right)$ in $\mathrm{NaCl}$ solutions. J Solut Chem. 2002;31(2):97-108. https://doi. org/10.1023/A:1015275618138.

Strübel G. Die hydrothermale Löslichkeit von Cölestin im System $\mathrm{SrSO}_{4}-\mathrm{NaCl}_{2} \mathrm{H}_{2} \mathrm{O}$. Neues Jahrb Min. 1966;99:107.

Strübel, G. Zur Kenntnis und genetischen Bedeutung des Systems $\mathrm{BaSO}_{4}-\mathrm{NaCl}-\mathrm{H}_{2}$. Neues Jahrb. Mineral. Monatsh. 1967:223-34.

Stumm W, Morgan JJ. Aquatic chemistry: Chemical equilibria and rates in natural waters. Environmental science and technology. 3rd ed. New York: Wiley; 1996.

Sverjensky DA, Shock EL, Helgeson HC. Prediction of the thermodynamic properties of aqueous metal complexes to $1000^{\circ} \mathrm{C}$ and 5 kb. Geochimica et Cosmochimica Acta. 1997;61(7):1359-412. https://doi.org/10.1016/S0016 $-7037(97) 00009-4$

Tanger JC, Helgeson HC. Calculation of the thermodynamic and transport properties of aqueous species at high pressures and temperatures; revised equations of state for the standard partial molal properties of ions and electrolytes. Am J Sci. 1988;288(1):19-98. https://doi.org/10.2475/ajs.288.1.19.

Templeton CC. Solubility of barium sulfate in sodium chloride solutions from $25^{\circ}$ to $95^{\circ} \mathrm{C}$. J Chem Eng Data. 1960;5(4):514-6. https://doi.org/10.1021/je60008a028.

Turner D, Whitfield M, Dickson A. The equilibrium speciation of dissolved components in freshwater and sea water at $25^{\circ} \mathrm{C}$ and $1 \mathrm{~atm}$ pressure. Geochimica et Cosmochimica Acta. 1981;45(6):855-81. https://doi.org/10.1016/00167037(81)90115-0

Uchameyshvili NY, Malinin SD, Khitarov NI. Solubility of barite in concentrated chloride solutions of some metals at elevated temperatures in relation to problems of the genesis of barite deposits. Geochem Inter. 1966;277:70-7.

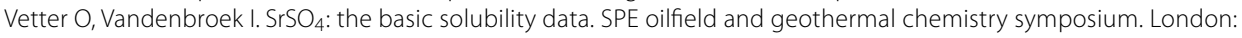
Society of Petroleum Engineers; 1983. https://doi.org/10.2118/11803-MS.

Visscher AD, Vanderdeelen J. IUPAC-NIST solubility data series. 95. alkaline earth carbonates in aqueous systems. Part 2. Ca. J Phys Chem Ref Data. 2012;41(2):1-137.

Visscher AD, Vanderdeelen J, Königsberger E, Churagulov BR, Ichikuni M, Tsurumi M. IUPAC-NIST solubility data series. 95. alkaline earth carbonates in aqueous systems. Part 1. Introduction, Be and Mg. J Phys Chem Ref Data. 2012;41(1):1-67. https://doi.org/10.1063/1.3675992.

Voigt M, Marieni C, Clark DE, Gíslason SR, Oelkers EH. Evaluation and refinement of thermodynamic databases for mineral carbonation. Energy Procedia. 2018;146:81-91. https://doi.org/10.1016/j.egypro.2018.07.012.

Wagner T, Kulik DA, Hingerl FF, Dmytrieva SV. GEM-Selekor geochemical modelling package: TSolMod library and data interface for multicomponent phase models. Can Mineral. 2012;50(5):1173-95. https://doi.org/10.3749/ canmin.50.5.1173.

Wagner W, Pruß A. The IAPWS formulation 1995 for the thermodynamic properties of ordinary water substance for general and scientific use. J Phys Chem Ref Data. 2002;31(2):387-535. https://doi.org/10.1063/1.1461829.

Wolery T. EQ3/6, a software package for geochemical modeling of aqueous systems: package overview and installation guide (version 7.0). Berkeley: Lawrence Berkeley National Laboratory; 1992.

Wolf M, Breitkopf O, Puk R. Solubility of calcite in different electrolytes at temperatures between $10^{\circ}$ and $60^{\circ} \mathrm{C}$ and at $\mathrm{CO}_{2}$ partial pressures of about $1 \mathrm{kPa}$. Chem Geol. 1989;76(3-4):291-301. https://doi.org/10.1016/00092541(89)90097-1.

Yan C, Guraieb P, Huang J, Tomson RC. Study of siderite solubility under extreme high temperature and pressure in 1 M NaCl solution. In: Paper 5623 presented at CORROSION 2015, Dallas, Texas. 2015. p. 15.

Yanat'eva OK. Solubility of dolomite in water salt solutions. Izvestiya Sektora FkhA Akademii Nauk SSSR. 1952;20:25268 (in Russian).

Yoon JS, Zang A, Stephansson O. Numerical investigation on optimized stimulation of intact and naturally fractured deep geothermal reservoirs using hydro-mechanical coupled discrete particles joints model. Geothermics. 2014;52:165-84. https://doi.org/10.1016/j.geothermics.2014.01.009.

Zhao Y, Feng Z, Feng Z, Yang D, Liang W. THM (thermo-hydro-mechanical) coupled mathematical model of fractured media and numerical simulation of a 3D enhanced geothermal system at $573 \mathrm{~K}$ and buried depth $6000-7000 \mathrm{M}$. Energy. 2015;82:193-205. https://doi.org/10.1016/j.energy.2015.01.030.

Zhen-Wu BY, Dideriksen K, Belova DA, Raahauge PJ, Stipp SLS. A comparison of standard thermodynamic properties and solubility data for baryte, $\mathrm{Ba}^{2+}(\mathrm{aq})$ and $\mathrm{SO}_{4}{ }^{2-}$ (aq). Mineral Mag. 2014;78(06):1505-15. https://doi. org/10.1180/minmag.2014.078.6.17. 